$$
\begin{aligned}
& \text { 颜 }
\end{aligned}
$$

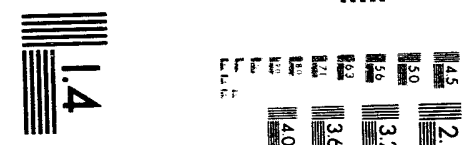

$$
\begin{aligned}
& \text { }
\end{aligned}
$$



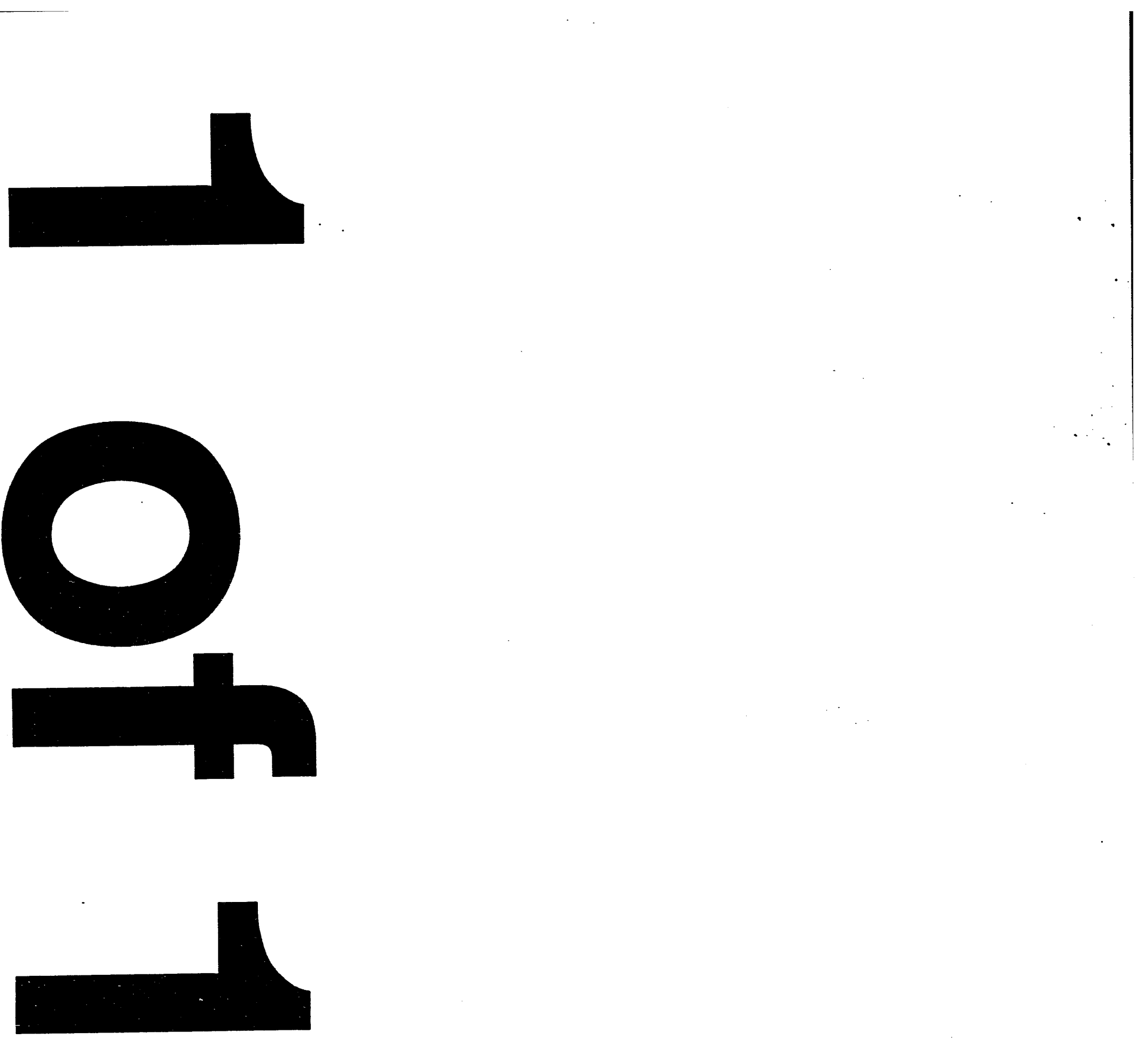
NUREG/CR-6103

SAND93-7107

\section{Prioritization of Reactor Control Components Susceptible to Fire Damage as a Consequence of Aging}

Manuscript Completed: July 1993

Date Published: January 1994

Prepared by

W. Lowry, R. Vigil/SEA

S. Nowlen/Sandia Project Manager

Science and Engineering Associates, Inc.

6100 Uptown Blvd.

Albuquerque, NM 87110

Under Contract to:

Sandia National Laboratories

Albuquerque, NM 87185

Prepared for

Division of Engineering

Office of Nuclear Regulatory Research

U.S. Nuclear Regulatory Commission

Washington, DC 20555-0001

NRC FIN A1833 


\begin{abstract}
The Fire Vulnerability of Aged Electrical Components Test Program is to identify and assess issues of plant aging that could lead to an increase in nuclear power plant risk because of fires. Historical component data and prior analyses are used to prioritize a list of components with respect to aging and fire vulnerability and the consequences of their failure on plant safety systems. The component list emphasizes safety system control components, but excludes cables, large equipment, and devices encompassed in the Equipment Qualification (EQ) program. The test program selected components identified in a utility survey and developed test and fire conditions necessary to maximize the effectiveness of the test program. Fire damage considerations were limited to purely thermal effects.
\end{abstract}




\section{Table of Contents}

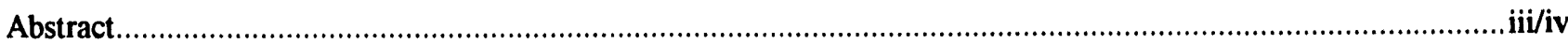

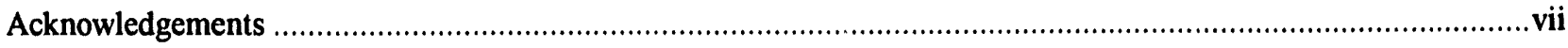

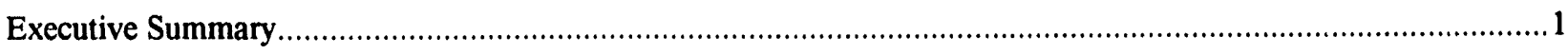

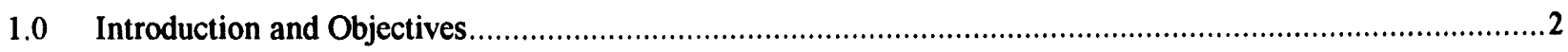

2.0 Identification of Generic Components for Aging/Fire Testing ..............................................................

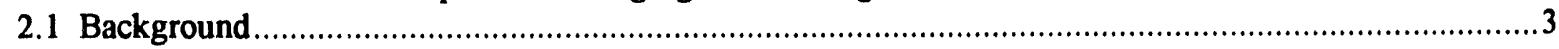

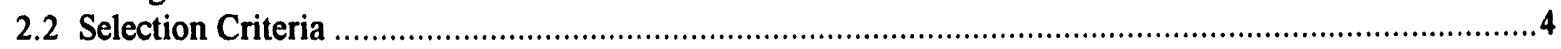

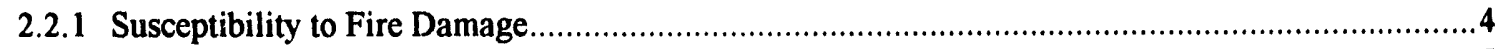

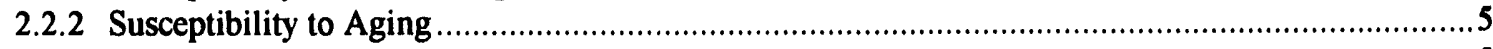

2.2.3 Consequence of Component Failure ........................................................................................

2.2.4 Recommended and Prioritized Component List .....................................................................6

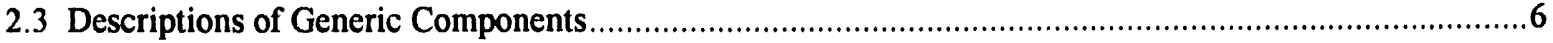

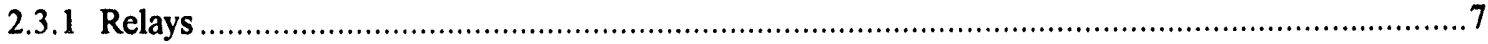

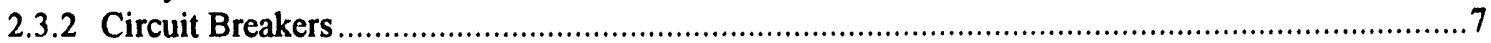

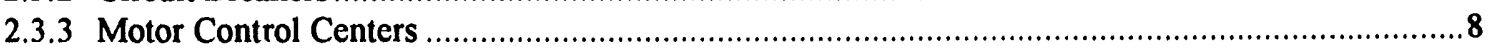

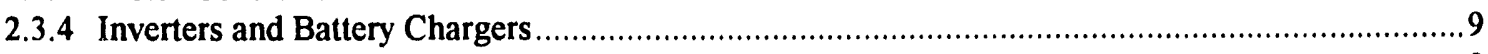

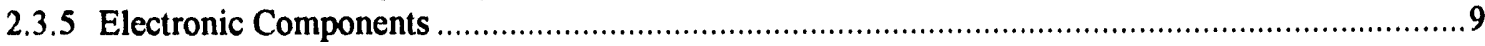

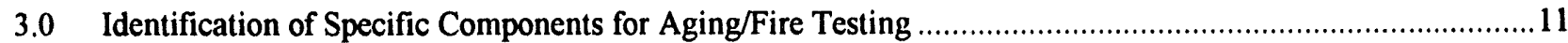

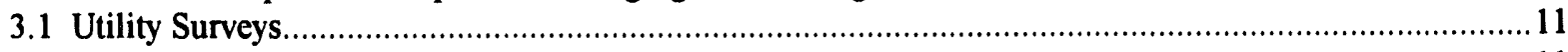

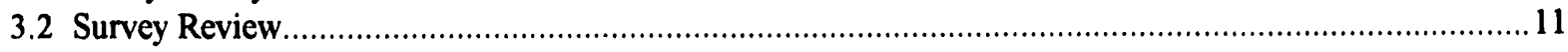

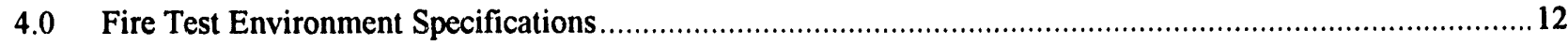

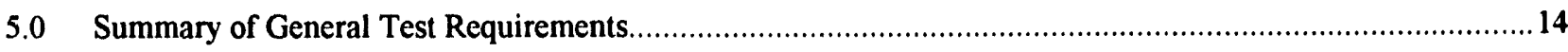

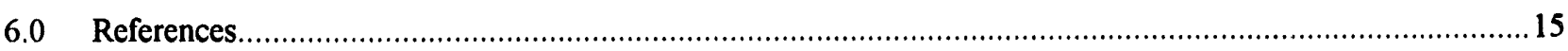

Appendix A:IEEE Std. 500; High Temperature Environmental Multipliers .................................................. A-1 


\section{List of Figures}

Figure 1 General Categories of Components Considered for Aging/Fire Test Program.

Figure 2 Generalized Fire-Induced Temperature Environments Resulting from Sandia Cabinet and Room Effects Tests.

\section{List of Tables}

Table 1 Equipment summary ranking considering the impact of fire-induced damage on the functionality of the component

Table 2 Multipliers used to alter (increase) the predicted failure rates for control and support components when considering exposure to high temperature environments

Table 3 Fraction of reported NPRDS component failures attributed to aging.

Table 4 Number of reported NPRDS component failures attributed to aging

Table 5 Total failures (age-related and otherwise) studied in the failure-cause analysis of Auxiliary Feedwater, Class 1E, High Pressure Injection, and Service Water Systems of a selected number of Plants (Westinghouse, Babcock \& Wilcox)

Table 6 Total failures from failure cause results in Table 5 ordered by the number of failures which affected system operation (Significant Failures)

Table 7 Component group with the highest overall ranking with respect to fire susceptibility and potential for degradation of plant system operations.

Table 8 Component group with the intermediate overall ranking with respect to fire susceptibility and potential for degradation of plant system operations

Table 9 Component group with the lowest overall ranking with respect to fire susceptibility and potential for degradation of plant system operations

Table 10 High priority component survey results

Table 11 Intermediate priority component survey results

Table 12 Generalized peak fire-induced air temperature environments for components, based on Sandia cabinet and room effects tests.

Table 13 Proposed general test requirements for the high priority component list 30

Table 14 Proposed general test requirements for the intermediate priority component list 


\section{Acknowledgements}

Our appreciation is extended to all who contributed to this effort. Steve Nowlen of Sandia National Laboratories provided guidance and technical support throughout this program. Michael Fletcher of CFA, Inc. helped in obtaining the utility surveys. Special thanks goes to William Farmer and Christina Antonescu of the NRC for their assistance and guidance. 


\section{Executive Summary}

This document identifies the components and test environments for the Sandia National Laboratories (SNL) Fire Vulnerability of Aged Electrical Components Test Program. Historical component data and prior analyses are used to prioritize the list of components with respect to aging, fire vulnerability, and the consequences of their failure on plant safety systems. The component list emphasizes safety system control components, but excludes cables, large equipment, and devices encompassed in the Equipment Qualification (EQ) program. Two component lists are identified for inclusion in the aging and fire testing program. The high priority group includes relays, circuit breakers, transmitters, recorders, temperature switches, instrument computation modules, instrument isolation devices, controllers, meters, and logic equipment. The intermediate group consists of battery chargers, inverters, process switches and sensors, position/limit switches, indicating devices (lights, annunciators, etc.), power supplies, batteries, timers, valve operators, and switches/pushbuttons. The rationale for this categorization is provided in the body of this document. Sandia's fire test program results are used to define realistic temperature environments, of which a subset is recommended for the test components. The results of a utility survey identifying explicit component populations are summarized based on this priorization. Survey responses from 19 plants were used to create a data base to aid in component identification. 


\subsection{Introduction and Objectives}

The objective of the Fire Vulnerability of Aged Electrical Components Program is to identify and assess issues of plant aging that could lead to an increase in nuclear power plant fire risk. The effort described in this report addresses aging effects on the fire vulnerability of electrical components other than cables, which are treated in a separate test program at Sandia. The scope is limited further by excluding components located inside the containment building (encompassed in the Equipment Qualification program) and large equipment known to be less susceptible to fire damage. The emphasis is on control components, including sensors, indicators, decision making equipment (logic and control devices), actuation devices (relays, circuit breakers, and valve actuators), and support components (power supplies, batteries, inverters, etc.). Fire damage considerations are initially limited to purely thermal effects (excluding humidity, corrosion, fire suppression, and particulate damage mechanisms) as thermal effects are somewhat more straightforward to characterize and test and are the principal mechanisms considered in the fire risk studies.

Issues that have either been addressed in previous studies, or will be considered separately in the future, are the impact of aging on the vulnerability to fire damage of cables, cable protective features, and barrier penetration seals; the impact of aging on the susceptibility of electrical equipment to self-induced fires; and the impact of aging on fire detection and suppression systems.

The initial effort of the experiment design is to identify the components to be tested in the subsequent aging/fire test program at Sandia. The components selected must be vulnerable to aging degradation and fire damage, and their failure must adversely impact the operation of safety rolated systems in the plant. This impact can be through loss of redundancy, total loss of function, or degradation of performance. Generic classes of components are identified that satisfy these criteria. Aging and failure mechanisms are compiled for each class. Applicable accelerated aging methods are recommended, as well as environmental conditions for the fire exposure tests. A utility survey was conducted to identify specific component populations in use. The test program will select components identified in the survey and develop test and fire conditions necessary to maximize the effectiveness of the test program. 


\subsection{Identification of Generic Components for Aging/Fire Testing}

\subsection{Background}

The initial task for the aging/fire susceptibility experimental program was to identify the general classes of nuclear power plant components appropriate for evaluation. We address specifically the electrical control components (including sensing, indicating, decision making, power source, and power transmission devices) of the safety related systems. Components located inside the containment building, which have been subjected to the harsh environment EQ program, are excluded from this study. The extremely low incidence of fires in the containment building, the high temperature qualification conditions for these devices (typically longer than three hours at $174^{\circ} \mathrm{C}$ ), and their general ruggedness-by-design result in a relatively low priority for evaluation when compared with the out-ofcontainment components. Cables are treated in a separate Sandia research effort. Large equipment (pumps, turbines, blowers, etc.) is not evaluated because of its relatively low vulnerability to fire damage, primarily because of bulk. However, associated circuitry that is considered may cause the equipment to malfunction.

The components of interest operate in the plant safety systems and their associated support and power supply systems. The definition of "safety systems" is general. A precise list of appropriate systems to be considered in this program is difficult because of variations in plant type and the nature of the safety action required. The sources of aging, fire susceptibility, and reliability data referenced in this report used slightly different safety-related systems lists. In general, the following systems are considered:

\author{
Class 1E power distribution \\ Reactor protection trip \\ High and low pressure injection \\ Residual heat removal \\ Component cooling and service water \\ Main and auxiliary feedwater \\ Reactor coolant \\ Residual heat removal \\ Standby liquid control
}

The specific components to be tested are in many cases common across several systems. Their failure rates and aging susceptibility are not strongly system dependent. Consequently, for the purpose of this study, minimal attention will be applied to system dependencies as long as the component of interest is clearly required for safety actions.

The list of components is derived from an analysis of fire-related damage to safety equipment conducted by Wanless [1], with additions where noted. The components fall into four functional categories: 1) sensing and indicating devices, 2) control decision and action initiation devices, 3) the active equipment to be controlled, and 4) power supply/distribution and signal transmission components as shown in Figure 1.

The criteria by which the components are selected for the test program consider the following:

* The component must show evidence of general degradation with time (aging).

* The expected susceptibility of the component to fire damage must be significant.

* The consequence of failure of the component must be significant. This is either by virtue of its population in the safety systems, or its identified negative impact on safety system operations with component failure, or a combination of both high population and negative impact.

All components are susceptible to aging degradation, in varying degrees and in many different forms. The abundance of dielectrics in sensing, control, and transmission devices results in a demonstrated aging sensitivity, particularly when components are enclosed in cabinets with elevated internal temperatures. The repetitious operation of relays, circuit breakers, and switches leads to electrical/mechanical degradation, aggravated by dust accumulation on contact surfaces. The insulating coatings of coils are subject to degradation at minute entrapped air voids. Under extended elevated temperature conditions these can enlarge, resulting in dielectric breakdown and catastrophic failure of the component. Aging of many relevant control components has been studied in the Nuclear Plant Aging Research (NPAR) program. These studies have used recorded historical failure information from various data bases, which emphasize the endpoint of the aging cycle (component failure). They do not clucidate the continuous degradation process or its impact on fire susceptibility. The relative susceptibility of a component to aging-related failure, as inferred from historical data, is uscful in identifying the ficld of components susceptible to aging deterioration.

The available information on susceptibility to fire damage is limited, particularly for control components excluded from both the Equipment Qualification (EQ) program and cable studics. Manufacturers are primarily concerned with the adequate operation of their products within the specified environmental conditions (the 
upper temperature operating limit of most electrical control components is $40^{\circ}$ to $50^{\circ} \mathrm{C}$ ). Most fire studies are constrained to minimization of life and property loss, and consequently do not attempt to discern equipment failure modes or causes. The most relevant efforts are the detailed fire exposure tests and failure diagnostics of prior Sandia experimental programs, that will be used in this study.

The consequences of component failure are determined from historical records where the effects on system function have been noted. Probabilistic Risk Assessments and Final Safety Analysis Reports provide a broad view of the potential impacts of failures, but tend to be limited to system or, at most, sub-system level processes and are not helpful in the component prioritization. Appendix R submittals describe utility plans for reactor shutdown operations during fire events, identifying the systems necessary for safety functions. This information is used where appropriate.

This experiment design effort attempts to identify the field of components suitable for testing, and prioritizes the list since it will not be possible to test all components. In the following sections the generic classes of components are identified and prioritized, accompanied by their supporting rationale.

\subsection{Selection Criteria}

\subsubsection{Susceptibility to Fire Damage}

The vulnerability of components to damage by fire-induced environments is dependent upon the component design and its performance requirements. Wanless [1] considered both the "damage proneness" and the functional requirements to prioritize the components in Figure 1. Vendor data, fire damage reports, fire test results, and material properties were all considered to rank the components for their vulnerability to damage by high temperature, moisture, particulates, and corrosive vapors. Each of these effects carried a specified weight. In all cases temperature effects dominated. The component accuracy, sensitivity, and complexity of its outputs were factored into the final ranking. A maximum score of 1.0 indicated the greatest susceptibility to fire damage, 0.0 implied no effect. Of the 33 components ranked, the highest score was 0.79 (recorders) and the lowest 0.00 (pumps). As shown in Table 1, the components fall into four damage sensitivity groups. Sensitive, relatively complex instruments and electronics fill the highest category. Medium high scores occur with power switching devices, batteries, and instrumentation transmitters. Sensors, transformers, passive power transmission devices, small and unprotected motors, and remote valve actuators form the medium low category. The lowest score group consists of large, mechanical plant equipment: fans, heaters, valves, and pumps (because of this very low susceptibility to fire damage, the large equipment was not considered in the subsequent rankings in this report).

This ranking is reinforced by a list of environmental multipliers recommended by IEEE [2], shown in Table 2. The high temperature multiplier is applied to historical failure rate data to compensate for the effects of other normal and abnormal environments. For example, elevated temperature effects induced by a fire (typically greater than $38^{\circ} \mathrm{C}$ ) would require the application of the high temperature multiplier. Again, note that temperature sensitivity is largely a function of degree of dependence upon electronics, overall complexity, and, inversely, of the massiveness of the device.

As a follow-up to the Wanless review, a screening program by Jacobus [3] exposed several components to simulated and actual fire environments. The devices were exposed to high temperature fire simulations or were included in cabinet fire experiments, in conditions resulting from cable insulation fires inside the cabinets. The recorded peak temperatures in the cabinet tests ranged from $60^{\circ}$ to $195^{\circ} \mathrm{C}$. Hand switches, relays, meters, electronic counters, a power supply and a power amplifier all survived these exposures with minimal apparent degradation. An oscilloscope amplifier (not necessarily typical of any specific nuclear power plant equipment) experienced drift of up to $20 \%$ then shut itself down with a thermal cutoff switch. A chart recorder (of a type used in a nuclear power plant) failed to record because of particulate buildup on the pen slider. The variability in degree of damage to this suite of components was due in part to the wide range in temperature exposure, so a quantitative comparison is not possible. In separate experiments, exposure to temperatures as high as $270^{\circ} \mathrm{C}$ in a test chamber caused relay failure from socket warpage and electrical lead insulation failure. A useful feature of these screening tests is in the unexpected results, such as the general survival of relays at seemingly high temperatures with their failure occurring not in the relay internals but in connector blocks and electrical leads. The tolerance of the power supply and power amplifier to high temperatures is unexpected, as is that of the counter. Continuous monitoring (in the case of the counter) and application of realistic loads to the power supply and power amplifier may produce different results relevant to the functionality of the components under accident conditions. The relays that were tested in the thermal damage tests did include realistic loadings together with continuous monitoring and periodic functional checks during the exposures. 


\section{Identification of Components}

\subsubsection{Susceptibility to Aging}

In their aging failure survey of the Nuclear Plant Reliability Data System (NPRDS) data base Meale and Satterwhite [4] analyzed reported failures to ascertain the degree to which safety-related component failures could be ascribed to aging. Failures of components in safety and support systems were categorized as design and installation (engincering/design, manufacturing defect, or installation crror), aging (wearout), testing and maintenance (maintenance/testing), human-related (incorrect procedure, operating error), and other (other devices, cause unknown). More than 17,000) failures were included in the data base, whose population includes BWR and PWR safety and support system data gathered through 1986. Passive devices (pipes and supports) and large plant equipment (motors, blowers, valves, etc.) were included in the referenced study but only control components and their electrical support equipment are considered for this purpose. The results of the aging survey were used to infer the relative susceptibility specific components have to aging failure. The number of failures at tributed to aging for a given component was divided by the total number of failures (aging and otherwise) reported for that component, across all systems studied. That fraction is denoted as the aging fraction for the particular component. Table 3 lists the results, highest aging fraction first, and the systems considered in the study. This approach is intended to rank the equipment with respect to its tendency to fail because of age-related causes, versus other faiiure mechanisms. However, the total number of failures per component also provides useful information in the relative number of failures that occurred. Table 4 ranks these same components using the number of aging failures as the criterion.

Several results are relevant to the aging/fire safety program planning. Of the total number of failures reported, including major plant equipment and cables, $32 \%$ were considered to be caused by aging, $49 \%$ was due to other, and the balance of failures distributed among design and installation (10\%), testing and maintenance $(7.5 \%)$, and human-related $(1.5 \%)$. The subset considered as control and support components shows an overall aging fraction of $22 \%$ (Table 3), so on the whole these devices are not as susceptible to aging degradation as larger, more mechanical components. The components of Table 3 divide into three natural relative groups: high (.30) to .50), medium (.20).29), and low (0-.19). Annunciators, instrumentation isolation devices, and batteries show the highest susceptibility to aging failure. The lowest susceptibility group consists of transformers, instrument transmitters, and instrument process switches. The medium group is the largest (6.3\% of the total failures of the control/support subset, and $72 \%$ of the aging-related failures of the subset), including instrument components, relays and circuit breakers, valve operators, and generators/alternators/inverters.

Table 4 shows a different distribution when the ranking criterion is based solely upon the number of failures. The components of Table 4 divide into three natural relative groups: high (over 200 failures), medium (100-200 failures), and low (0-100 failures). Valve operators, instrument transmitters, instrument components, instrument switches, and circuit breakers comprise the group with the highest number of failures reported. The medium grouping consists of instrument recorders, relays, generators/alternators/inverters, instrument controllers, power supplies, and batteries. The low grouping consists of instrumentation isolation devices, transformers, cables and annunciators. A number of components moved from the high to low category or low to high category when comparing Table 3 with Table 4.

\subsubsection{Consequences of Component Failure}

Consequences of failure depend on several system design characteristics:

* Population of the component in the safety systems.

* Redundancy of the trains in which the component functions.

* Redundancy of the component within the train.

* Separation between components in redundant trains.

* Number of outputs to other systems/components (how many other functions does the component influence?)

* How fail-safe is the design under credible circumstances and to what extent does its failure degrade system operations?

One approach to ranking would be to review Final Safety Analysis Reports (FSARs) and Probabilistic Risk Assessments (PRAs) to quantify the representative significance of component failures. A cursory revicw of both FSARs and PRAs showed that these would not readily provide sufficiently general information for the components of interest. The authors chose to use NPRDS data obtained from the failure/cause analysis reported by Meale and Satterwhite $[4]$ as a historical record of the consequence of component failures. 
Failures, their causcs, and impact on system performance were analyzed for a selected group of plants (Westinghouse and Babcock \& Wilcox). The systems considered were Auxiliary Feedwater, Class 1E Electrical Distribution, High Pressure Injection, and Service Water. Note that, although similar systems exist in other plants, the physical systems will be different than the systems described in this study. For the purpose of this design, the results of the NPRDS study were compiled to illustrate the impact of component failures (independent of the cause of the failure) on plant system function. Impact on system function was categorized as Loss of System Function, Loss of Subsystem/Channel, Loss of Redundancy, Degraded System Operation, and System Function Unaffected. The results of the compilation and definitions of these impact categories are provided in Table 5 (no specific order). In Table 6 the number of failures impacting system operation (that is, excluding the category System Function Unaffected) were summed and the list ordered by that number. The utility of this categorization is in showing which components dominate the significant failures in safety systems. This ranking is sensitive to failure rate, since if a component does not fail, it will not impact safety operation (PRAs would yield a rigorous quantification of the potential impact of a component failure upon safety operations).

The ranking is dominated by motor and pneumatically operated valve failures. This is not surprising considering their high population in the plant, their mechanical nature, and the fact that most safety operations in the plant end in some sort of fluid control action. The other components in the High category are transmitters, controllers, circuit breakers, inverters, and process switches. The Medium group consists of indicators, chargers, relays, and recorders. The balance of the components occupy the Low category (switches, solenoid valves, transformers, batteries, buses, power supplies, and timers). An interesting parameter, the ratio of significant failures to total failures for each component, has been included in Table 6. For the components with few failures the statistics are trivial, but for the others this ratio indicates that failures for these components usually result in negative impact on safety system operation.

A useful perspective not available from failure data bases was gained from utility fire safety plans. Appendix R submittals for the Turkey Point and Surry plants were reviewed. Most of their content is devoted to cable vulnerability to fire damage, planned responses to fires occurring in the plant, and system functional requirements to implement these plans. The fire scenarios require operator decisions and action based on indications of the plant condition. Visual and audio indicators (meters, recorders, lights, gauges, and annunciators) are all necessary sources or operator action. The operator environment must also be suitable for emergency response; hence, functioning emergency lighting, communications, and ventilation are necessary. It is difficult to incorporate the significance of these functions quantitatively into the proposed ranking. They are mentioned here as a reminder that some of the less obvious components and support systems perform significant roles in emergency actions.

\subsubsection{Recommended and Prioritized Component List}

Rankings from the three previous sections were combined into a prioritized summary list of generic components for the subsequent test program. Fire susceptibility is ranked according to the survey by Wanless (Table 1) with the ranking categories normalized because the lowest category components will not be considered in this survey. Hence, Medium High is changed to Medium, and Medium Low is now Low for the fire susceptibility ranking. The impact on safety operations ranking is from the NPRDS failure cause survey (Table 6). The aging rank is derived from the NPRDS aging survey (Tables 3 and 4).

Table 7 lists the components with the highest overall ranking, Table 8 the intermediate components, and Table 9 the lowest. The intent was to make the overall ranking sufficiently general such that it is not overly sensitive to uncertainties and limitations of the original numerical rankings. The overall ranking was determined by first ranking components based upon their fire susceptibility and their impact on safety operations. The components were then re-evaluated using the aging fraction and aging failure data. Although within each of the three tables the components can be ranked in greater detail, the intent is to treat the components in the indicated groups. Hence, the Table 7 group is recommended as the highest priority list of components to be tested in the Sandia aging and fire testing program, followed by the Table 8 components. The Table 9 group should be the lowest priority for testing.

\subsection{Descriptions of Generic Components}

The NPAR program has investigated several nuclear plant components with respect to their general reliability, aging susccptibility, and in-place operating environment for the purpose of understanding plant aging processes. Relays, circuit breakers, inverters/battery chargers, and motor control centers, all falling within the highest or intermediate priority component group, have been studied and the results will be summarized here. Other components will be described as information is available. 


\subsubsection{Relays [5]}

\section{Description and Function}

Relays constitute one of the highest general component populations in nuclear plants. Those included in safety-related applications fall into four functional categories:

Protective relays -- Protect the plant power distribution systems from electrical overloads and failures. Specific protective functions include undervoltage, instantaneous overcurrent, time overcurrent, and differential voltage or current. Depending on the application, these relays may be of the solenoid, induction disc, armature, or, in very smail numbers, solid state design. As many as 400 protective relays will be present in the safety systems of a nuclcar plant.

Auxiliary relays -- Provide supplementary relaying to protective relays for multiplication of relay contacts and carrying larger loads (up to 35 amperes). These are typically of the armature design, although some use solenoids.

Control relays -- On/off device used in logic switching functions as well as direct control of components such as valves, usually of the solenoid design with the smaller fraction being armature relays. Solid state electronic relays are used in some control functions (in very small numbers). Control relays constitute one of the greatest equipment populations in a nuclear plant.

Time delay or timing relays -- Typically a control relay coupled to a timing device, these relays do not actuate their contacts until a prescribed time period has elapsed after receipt of an input signal. The timing device may be either pneumatic (employing a solenoid actuated pneumatic diaphragm with an adjustable orifice), mechanical (timing motor, cams, and clutches) or electronic (resistor/capacitor network).

\section{Relay Failure Modes:}

Failure to open or close when commanded Opens or closes without command Does not make or break current

Fails to carry current

High contact resistance

Setpoint shift

Time delay shift

\section{Relay Failure Causes:}

Power-to-ground short

\author{
Coil insulation breakdown \\ Contact wear \\ Binding of contacts because of warpage of \\ contact carriers \\ Pitting, corrosion, and accumulation of \\ contaminants on contacts \\ Wear of moving parts \\ Loss of integrity of relay pin/socket \\ connection \\ Vibration damage: contact chatter, loosening \\ of connections \\ Shift in resistance and capacitance values \\ affecting time delay and relay setpoint values
}

\section{Dominant Aging-related Stresses for Relays:}

Thermal aging of synthetic parts because of continuous energization or elevated temperature inside cabinet: case, coil wire insulation, bobbins, lead wire insulation, diaphragm (inductive disc relays only), contact carriers, baseplate and socket.

Frequent cycling of relay causing contact degradation and winding degradation because of inductive surge.

\section{Relay Test Diagnostics:}

Test methods for relays are well developed [6]. The following measurements are common diagnostics. Some would be applied before and after aging and fire exposure, while others would monitor the relay performance during the fire test:

Contact resistance

Insulation resistance

Dielectric withstanding voltage

Winding resistance, inductance, and impedance

Contact chatter

Electrical characteristics during actuation (voltage, current)

Pickup voltage/current surge

Drop-out voltage

Actuation timing

\subsubsection{Circuit Breakers [5]}

\section{Description and Function}

Circuit breakers switch power loads/sources and interrupt faults. The same type, and in fact the same breaker, can perform both functions. In safety systems, circuit breakers typically operate up to 13,000 Volts ac. The two basic designs are metal-clad and molded-case 


\section{Identification of Components}

breakers. Metal-clad circuit breakers are used in $480 \mathrm{~V}$ and above circuits, where they feed larger more significant loads (possibly important safety loads). These are sophisticated devices, capable of repetitious operation under high loads, and are normally controlled remotely. A typical nuclear plant will have 250 metalclad breakers. They are associated with, and located near, major bus systems, and designed to interrupt fault currents of 25,000 to 150,000 amperes. Molded case circuit breakers are much simpler and smaller, housed in a phenolic case, and operate in the $480 \mathrm{~V}$ and lower circuits for small loads. Several hundred molded case breakers may be present in a typical plant.

\section{Circuit Breaker Failure Modes:}

Failure modes for circuit breakers are similar to those of relays. Circuit breakers have fewer control function built into them other than overcurrent or undervoltage protection (their control operation is usually dictated by a control or other type of relay). Failures are typically failure to make/break on command, inadvertent make/break, excessive contact current, or current/voltage setpoint drift.

\section{Circuit Breaker Failure Causes:}

Contact degradation

Phase-to-ground fault

Phase-to-phase fault

Coil insulation breakdown

Housing and contact insulation breakdown

Heating/annealing of the bimetallic strip for overcurrent detection

Loosened connections

Reduced contact force

Degradation of lubricant

\section{Dominant Aging Related Stresses for Circuit Breakers:}

Overheating because of high contact resistance or large fault currents, causing casing warpage, loss/degradation of lubricant, and accelerated dielectric breakdown.

Extreme voltage gradients, causing excessive arcing and contact material vaporization with subsequent deposition on insulator surfaces.

Cyclic operation and fault interruption, inducing mechanical wear and loosening of connections.

\section{Circuit Breaker Test Diagnostics:}

Contact resistance

Phase-to-phase and phase-to-ground

resistance

Overcurrent and undervoltage trip point

calibration

Trip timing

Coil resistance

\subsubsection{Motor Control Centers [7]}

\section{Description and Function}

Motor control centers (MCCs) are large cabinet mounted systems that provide control and power to relatively small induction type $\mathrm{AC}$ motors throughout the power plant (small being less than 100 horsepower and 600 Volts). A typical nuclear plant may have 1000 motors of this class, evenly distributed between valve operators and pumps/fans. An MCC cabinet will typically control several motors, and 40 to 80 cabinet sets, cach consisting of several cabinets will be located throughout the plant. Motor control centers serve other vital systems, including battery chargers, inverters, diesel generator auxiliary systems, and heating and air conditioning components.

The basic function of the MCC is twofold: (1) providing a means of starting and maintaining continuous electrical power to motors, and (2) controlling these motors in the performance of their functions. In its most basic form, the MCC consists of:

Molded case circuit breakers -- Break the power supply circuits to the motor windings under overload or fault conditions.

Magnetic contactors -- Open and close the supply circuits to the motor windings for normal on/off operation.

Thermal overload relays -- Overcurrent protection devices on each of the motor windings protect the motor from continuous high current (such as overloaded conditions).

Control transformer -. A step-down transformer that taps off the high voltage motor supply to provide $120 \mathrm{Vac}$ to the control circuitry.

Motor control centers may also perform other functions, including motor reversing, jogging, or inching; speed variations; and motor sequence control. For these other roles, the MCC will contain, in addition to the basic components listed above, interlocks, break 
and clutch controllers, distribution panels, solenoids, timing devices, pilot devices, and control relays. Safety-related control centers differ from their nonsafety counterparts in the use of redundant contactors in the power feed lines. An MCC cabinet is typically 90 inches high and 14 to 20 inches deep. Cabinet sets are located adjacent to each other, hence many motors will frequently be controlled from one location. The MCC cabinets are NEMA 12 units, and each individual motor controller is contained within its own bay inside the cabinet.

Failure modes, failure causes, and aging stress mechanisms of MCCs are similar to their subcomponents (i.e., relays, contactors, circuit breakers, transformers). Half of all motor control center failures are attributed to relays and circuit breakers. Thermal overloads and magnetic contactors cause the majority of the balance of failures. The dominant aging mechanism of MCCs was determined to be buildup of dust on electrical contacts. A thorough breakdown of subcomponent materials and their aging susceptibility is provided in Reference 7.

Because of the size and complexity of MCC's, it is likely that the most effective approach will be to individually test the failure-prone subcomponents.

\subsubsection{Inverters and Battery Chargers [8]}

\section{Description and Function}

Inverters and battery chargers are treated together because of their similarity in design and construction. Inverters produce ac power from dc bus input. Battery chargers maintain the backup batteries at full charge and support other dc loads. Both components are found in reactor protection systems, emergency core cooling systems, reactor core isolation systems, and ac/dc distribution systems. Inverters in particular tend to fail with significant consequences. In a 9 year recording period, 42 inadvertent reactor trips were caused by inverter failures. Several emergency core cooling system and safety injection system actuations also occurred inadvertently from inverter failures. Battery charger failures have caused dc bus degradation, diesel generator inoperability, and loss of control room annunciation and indication.

Inverters are of four designs: ferroresonant transformer, pulse-width modulated, quasi-square wave, and step wave inversion. The first two types constitute over $80 \%$ of those installed. They typically consist of molded case circuit breakers, transformers, integrated circuits, silicon controlled rectifiers (SCRs), diodes, relays, switches, terminal blocks, fuses, and basic electronic components (transistors, resistors, capacitors, etc.). Battery chargers are of three types: SCR solid state (over $75 \%$ of those in service), controlled ferroresonant, and magnetic amplified. A "typical" inverter will support a $7.5 \mathrm{kVA}$ load, weigh 1000 to 1500 pounds, and be housed in a metal cabinet for wall or floor mounting.

Inverter and Battery Charger Failure Modes:

Failurc to provide inverted output (inverter) Degraded ac waveform output (inverter) Failure to support dc load (battery charger) Degraded dc output (battery charger)

\section{Inverter and Battery Charger Failure Causes:}

Electrical stress because of loss of off-site power

Overheating

Subcomponents prone to failure from these stresses:

Fuses (dominant for electrical stresses)

Circuit breakers

SCRs

Capacitors

Diodes

Circuit boards

\section{Dominant Aging-Related Stresses for Inverters/Chargers:}

Elevated temperature (dominant)

Repeated loading from loss of off-site power

Inverter/Charger Test Diagnostics:

A test program evaluating naturally aged inverters and chargers presents detailed measurement designs to monitor device output [9]. The following parameters were observed:

Inverter output waveform

Battery charger output under load

Electrolytic capacitance valucs

Temperature rise of magnetics

\subsubsection{Electronic Components}

Several electronic components are included in the high priority ranking of Table 7: instrumentation isolation devices, computation modules, logic equipment (which could consist of solid state logic devices or relays), and controllers. These components do not have the obvious failure modes of the more mechanical devices discussed previously. They can, however, seriously impede safety operations without complete 


\section{Identification of Components}

component failure. Since they tend to be decisionmaking and action-initiation devices, in many cases with multiple outputs, their potential impact on safety systems is significant. This is illustrated by the serious threats posed by electronic failures, because of temperature excursions caused by poor ventilation, at McGuire Station, Davis-Besse, Palo Verde Unit 1, and Summer 1 [10]. In each case ventilation deficiencies or failures caused the environments of critical electronic components to exceed their temperature ratings, resulting in spurious signals or outright component failure which impeded operator response.

Electronic components typically have lower acceptable operating temperature ranges than the other components considered in this study; hence they are usually located in relatively controlled environments. For devices relying on operational amplifiers (isolation amplifiers, controllers, analog computation modules) the resistive feedback loop dictates the relation between the input and output of the device. Resistors are inherently sensitive to temperature, although manufacturers minimize the effect through compensation or use of low temperature coefficient resistors. One of the failures in the screening tests by Jacobus [3] was thermal drift of an instrument amplifier (the particular amplifier tested was not nuclear qualified, hov'ever). It is significant that thermal drift can occlis: undetected, without obvious failure, in many of these components. Digital logic devices suffer similar degrees of sensitivity to temperature, but fail in a more discrete (on/off) fashion.

The relevance of this to the Sandia program is that temperature environments that might otherwise be considered benign (such as $60^{\circ} \mathrm{C}$ ) will provide a great deal of information on the functionality of electronic components. The likelihood is high that many electronic components will see this environment in credible fire scenarios (see Section 4.0).

Aging of electronic components is complex because of the inhomogeneous mix of materials and subcomponents typical of electronic assemblies. A fairly complete assessment of the state of knowledge on electronic component aging is provided by EPRI [11]. In that report it was concluded that of the many subcomponents forming electronic devices, integrated circuit chips are to be the most susceptible to aging. Thermally accelerated aging appears to be the most appropriate simulation for these components. 


\subsection{Identification of Specific Components for Aging/Fire Testing}

\subsection{Utility Surveys}

The initial effort of the experiment program was the identification of specific components for fire exposure testing. The approach taken to obtain the information was a Nuclear Regulatory Commission NPAR Request for Information (survey). Utilities were asked, through the NRC, to complete the survey and return it to the NRC. The NRC informed the utilities that the identity of the respondents would not be provided. After removing the cover sheets, the NRC forwarded the responses to Sandia. Respondents were distinguished only by reactor type and by approximate year of attaining its operating license.

A total of 19 responses were received. The responses were in one of two formats. The res,ponse was either a completed request (survey) or a mild environment equipment list ( $q$-list). Below is a breakdown showing the responses by reactor supplier and operating licenses:

9 Westinghouse plants with operating licenses from the late 1960's to mid 1980's.

7 General Electric plants with operating licenses from the early 1970's to mid 1980's.

2 Combustion Engineering plants with operating licenses from the early 1970's and mid 1980's.

1 Babcock \& Wilcox plant with an operating license from the mid 1970's.

$\overline{19}$ Total Responses
Of the 19 responses, ten were completed requests and nine were mild environment equipment lists. The responses covered the desired range for operating licenses and reactor suppliers.

\subsection{Survey Review}

The survey responses were reviewed individually and components were grouped into individual lists. The components were entered into a personal computer data base for easier extraction. Logic equipment and gauges are the only components that did not yield any survey results. Several components, relays for example, constitute a large population and thus only base model types are listed. Some survey responses were vague, incomplete, or uninterpretable. The total population is derived from the responses and from judgments based on the information provided. The results shown can be expected to include some erroneous data.

Tables 10 and 11 show a simplified list of results. All quantities are based on the 19 plants surveyed. The components shown represent the high and intermediate priority component lists. At least one model is listed for each component. These models had the greatest percent of the total component population. The total population is also shown to give an idea of the population of each of the types of components. 


\subsection{Fire Test Environment Specifications}

It is not straightforward to generalize the fireinduced thermal environment to which the components will be exposed. Variations in geometry, combustible fuel loading and type, and ventilation rate all influence the heat flux or temperature experienced by the components. We will rely on prior Sandia fire test programs, which treated the specific conditions of interest (fircs in rooms and cabinets representative of nuclear power plant control room configurations), for specification of the thermal environments.

In room and cabinet effects tests $[12,13,14]$ fires of varying sources, and at varying positions, were initiated in enclosure configurations and sizes typical of nuclear plant control rooms. Vertical and benchboard cabinets were arranged in the test enclosure so the internal environments of the cabinets could be monitored. Fuel loadings typical of the amount of cable insulation found in control room cabinets, and with representative room ventilation rates, reproduced the environment expected from cable fires. In several cases, cable insulation was the actual fuel of the tests.

For the purposes of this study, the test results implied four natural categories of air temperature environment to which components would be subjected (Figure 2). The least severe cnvironment is the configuration in which the fire occurs on the floor of the room and the component is either free-standing in the room or contained within an open cabinet. While the air temperature directly above the flame source was probably several hundred degrees Celsius, only a few feet off to the side and six feet above the source the peak temperature was about $60^{\circ} \mathrm{C}$ (see Baseline Validation Test \#5 [12]). This is probably realistic for components housed in open cabinets and free-standing large components (switchgear and motor control centers, for example) close to a fire on the open floor of the room. This is also an environment representative of a fire contained inside a cabinet, and the component of interest either free-standing in the room or located in an open cabinet separated from the source cabinet by several feet (see Room Effects Test \#24 [14]). As long as the room is ventilated, components in closed cabinets separated from the fire source will most likely not experience air temperatures in excess of $50^{\circ} \mathrm{C}$. The exceptions to this are devices with some exposure on the surface of cabinets, such as panel meters, analog controllers, indicating lights, and switches, all of which could see the $60^{\circ} \mathrm{C}$ environment.

The next level of severity in temperature exposure would be the environment inside a cabinet immediately adjacent to a cabinet in which a fire occurs. In several of the room and cabinet effects tests (see Preliminary Cabinet Tests \#2 and \#5 [13]), a peak air temperature of $75^{\circ}$ to $100^{\circ} \mathrm{C}$ was measured in the upper portion of a cabinet adjacent to the cabinet containing the fire. Internal wall temperatures much higher than this were measured, but we presume that the components of interest are not mounted on or very close to cabinet walls.

A severe environment almost certain to fail any component is that inside a cabinet in which a fire occurs. The peak air temperature of approximately $900^{\circ} \mathrm{C}$ occurred rapidly and was typical of cabinet fires with open doors (see Preliminary Cabinet Tests \#2, \#5, \#6 [13]). In an early test with closed cabinet doors, a substantially lower peak temperature of $300^{\circ} \mathrm{C}$ was observed, attributed to a restricted air supply to the fire.

The most severe environment is that in the plume directly above a well ventilated fire. Measurements of the flame and plume temperatures were not intentionally obtained in the Sandia tests, but environments greater than $1000^{\circ} \mathrm{C}$ are expected. This extreme condition, expected to be of shorter duration than bulk air temperature peaks in other parts of the room, is likely to destroy any component it engulfs.

We have considered only the thermal stresses induced by elevated air temperature, as a simplification. The radiative flux on a component from flames is heavily dependent upon geometry and smoke opacity. In the Sandia tests with cable insulation as the fuel, smoke generation was significant. Radiative flux incident upon calorimeters tended to drop off at the end of the fire growth phase, although it imposed a higher heat flux on the calorimeters than the true air temperature up to that point. The gas temperature, although lower, was sustained for a longer period of time.

Figure 2 also shows the general temperature history for the different cases. A rapid peak occurring ten minutes after initiation of the fire is typical of the two higher conditions where the component would be in relatively close proximity to the flame. A broader, slower peak at twenty minutes was typical of measurements taken with either physical barriers or distance separating the component and the flame source.

There is a clear delineation of the number of components likely to experience each environment. The $60^{\circ} \mathrm{C}$ tempcrature history, although more benign than the others, is significant because with any given fire 
scenario many more components will experience this temperature stress compared to the relatively few that would experience the elevated temperatures inside or adjacent to a cabinet fire. The two dimensional temperature profiles of Baseline Validation Test \# 5 [12] showed that, at the six foot elevation, within a horizontal radial distance of approximately ten fect from the fire source, the air temperature had dropped to $50^{\circ} \mathrm{C}$. The components exposed to the $100^{\circ} \mathrm{C}$ environment would be those in adjacent, physically attached cabinets. The smallest population would be the components located inside a cabinet containing a fire or directly in the fire plume. An estimate of the relative number of components likely to be exposed to a given fire condition would be:

$\begin{array}{ll}>900^{\circ} & \begin{array}{l}\text { fire in cabinet, component in same cabinet, } \\ \text { or component in fire plume: } \\ \text { fire in cabinct, component in adjacent }\end{array} \\ 100^{\circ} \mathrm{C} & \begin{array}{l}\text { cabinet: } \\ \text { fire in cabinct or room, component within } \\ \text { ten feet of fire: }\end{array} \\ 60^{\circ} \mathrm{C} & >5\end{array}$

The component list is reproduced in Table 12 , indicating the type of environment each component will likely experience. The organization of components with respect to the different peak temperatures was based upon one of three probable physical configurations in the plant:(1) enclosed in a cabinet, but with some parts panel mounted (switches, indicators, recorders, etc.); (2) totally enclosed in a cabinet (power supplies, relays, circuit breakers, distribution panels, ctc.); and (3) standing alone exposed to room air (large or selfprotected components). Note that the table represents external cvents affecting each component, such as would occur with a cable fire. That is, the component is not considered to be the source or fuel of the fire.

The objective of this program is to understand the effects of aging on the fire vulnerability of components. The fire environments identified here are considered credible and should be used as a source of general guidance in the design of experimental exposures. However, it is unrealistic to expect component survival in $900^{\circ} \mathrm{C}$ or greater environments for the durations typical of these fires, and testing in this range would only demonstrate the obvious. Consequently, it is recommended that the actual design of thermal cxposures should consider not only the fire experience data, but also the likely thermal damage limits of the particular component under investigation. That is, one objective of any thermal component exposure will likely be to explore the thermal fragility limits. Hence, the experimental design should allow for thermal exposures that are eventually expected to result in component failure, within reasonable limits. It then becomes the task of the the risk analyst to interpret and apply the results. 


\subsection{Summary of General Test Requirements}

The categorization exercises resulted in a prioritized list of general components for the aging/fire vulnerability test series. The following requirements are proposed as the basis for a defensible and relevant research effort:

* Components should be exposed to realistic and relevant environments, in physical configurations typical of plant installations.

* Aging prior to the exposure tests should emphasize stressors known to degrade the component. These may be operational cycling, elevated temperature, or another component specific stress. The accelerated aging mechanism should be simple and well understood.
* During the fire exposure simulation, the component should be operating and loaded as it would normally be in the plant. Depending on the component, steady or cycling operation may be appropriate.

* Diagnostics should be unambiguous and should easily show pass/failure of straightforward failure criteria.

The general test matrix is depicted in Table 13 (high priority) and Table 14 (intermediate priority). These tables list the components, conditions during exposure tests, probable accelerated aging mechanisms, proposed temperature exposure environments, and general diagnostic requirements. For each component, it is assumed that pre- and post-test checks are conducted (such as calibration verifications) in addition to the continuous monitoring recommended in the test matrix. 


\subsection{References}

1. Wanless, J., "Investigation of Potential Fire-Related Damage to Safety-Related Equipment in Nuclear Power Plants," NUS Corporation, NUREG/CR-4310 (SAND85-7247), November 1985.

2. "IEEE Guide to the Collection and Presentation of Electrical, Electronic, Sensing Component, and Mechanical Equipment Reliability Data for Nuclear-Power Generating Stations," The Institute of Electrical and Electronics Engineers, Inc., IEEE Std 500-1984, Wiley Interscience.

3. Jacobus, M., "Screening Tests of Representative Nuclear Power Plant Components Exposed to Secondary Environments Created by Fires," Sandia National Laboratories, NUREG/CR4596 (SAND86-0394), June 1986.

4. Meale, B.M., and Satterwhite, D.G., "An aging Failure Survcy of Light Water Reactor Safety Systems and Components," EG\&G Idaho, Inc., NUREG/CR-4747 (EGG-2473) Vol. 2, July 1988.

5. Toman, G.J., Bacanskas, V.P., Shook, T.A., and Ladlow, C.C., "An Aging Assessment of Relays and Circuit Breakers and System Interactions," Franklin Research Center, NUREG/CR-4715 (BNL-NUREG- 52017), June 1987.

6. "Engineer's Relay Handbook," The National Association of Relay Manufacturers, Hayden Book Company.

7. Shier, W., Subudhi, M., "Operating Experience and Aging Assessment of Motor Control Centers," U.S. Nuclear Regulatory Commission, Office of Nuclear Reactor Research (NUREG/CR-5053), July 1988.
8. Gunther, W.E., Subudhi, M., and Taylor, J.H., "Operating Experience and Aging-Seismic Assessment of Battery Chargers and Inverters," Brookhaven National Laboratory (NUREG/CR4564), June 1986.

9. Gunther, W.E., "Testing of a Naturally Aged Nuclear Power Plant Inverter and Battery Charger," Brookhaven National Laboratory (NUREG/CR-5192), September 1988.

10. Chiramal, M., "Case Study Report: Effects of Ambient Temperature on Electronic Components in Safety-Related Instrument and Control Systems," U.S. Nuclear Regulatory Commission, Office for Analysis and Evaluation of Operational Data (AEOD/C604), December 1986.

11. Carfagno, S.P., and Gibson, R.J., "A Review of Equipment Aging Theory and Technology," Franklin Research Center (EPRI NP-1558), September 1980.

12. Nowlen, S.P., "Enclosure Environment Characterization Testing for the Base Line Validation of Computer Fire Simulation Codes," Sandia National Laboratories, NUREG/CR4681, March 1987.

13. Chavez, J.M., "An Experimental Investigation of Intcrnally Ignited Fires in Nuclear Power Plant Control Cabinets: Part 1: Cabinet Effects Tests," Sandia National Laboratories, NUREG/CR-4527/1 of 2 (SAND86-0336), April 1987.

14. Chaver, J.M., Nowlen, S.P., "An Experimental Investigation of Internally Ignited Fires in Nuclear Power Plant Control Cabinets: Part II: Room Effects Tests," Sandia National Laboratories, NUREG/CR-4527 (SAND860336 Vol. 2), November 1988. 


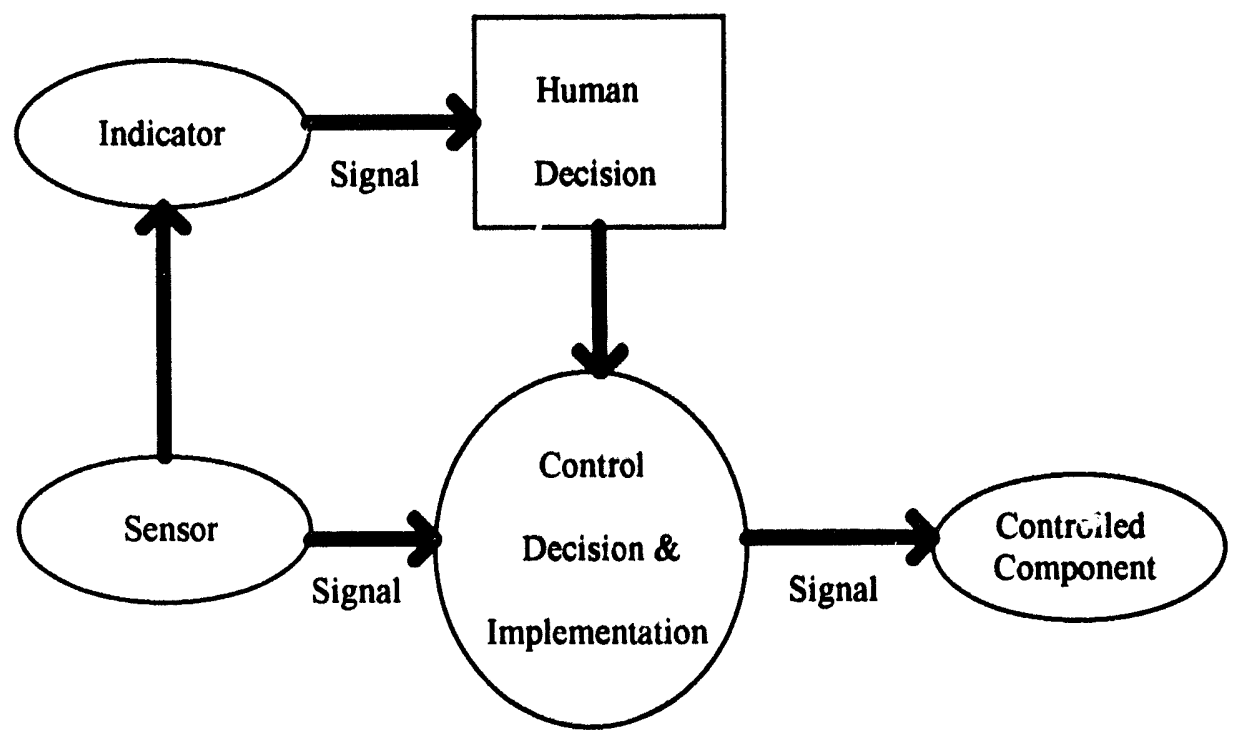

\section{Sensing/Indicating}

Recorders

Meters

Transmitters

(Pressure, Temperature, Flow)

Isolation Devices

Process Switches

(Pressure, Temperature,

Position/Limit)

Indicating Lights

Thermocouples and RTDs

Gauges

\author{
Control Decision and Action \\ Initiation \\ Logic Equipment \\ Controllers \\ Computation Modules \\ Timers \\ Solid State Relays \\ Electromechanical \\ Relays/Contactors \\ Circuit Breakers \\ Hand Switches/Pushbuttons \\ Motor Control Centers \\ Switchgear
}

$\underline{\text { Active (Controlled) Equipment }}$

Solenoid Valves

Valve Positioners/Operators

\section{Power Supply/Distribution and Signal}

Transmission

Battery Chargers/Inverters

Batteries

Common to all three:

Distribution Panels

Control Transformers

Power Transformers

Terminal Blocks

Note: Components missing from this figure, because they are not included in this test program, are cables and bulky controlled components (i.e., large motors and pumps).

Figure 1. General Categories of Components Considered for Aging/Fire Test Program. 
Enclosure (room)

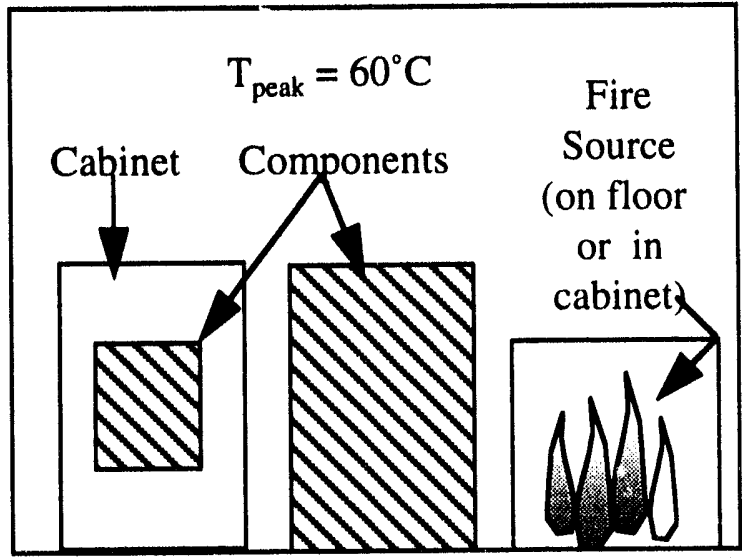

Component either free-standing or housed in cabinet, in same room as fire located in a cabinet or on the room floor

\section{Enclosure (room)}

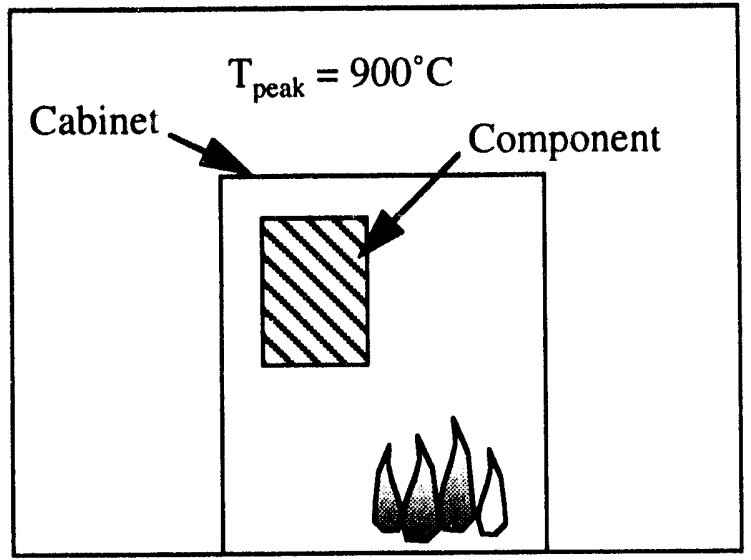

Component located inside the cabinet containing the fire
Enclosure (room)

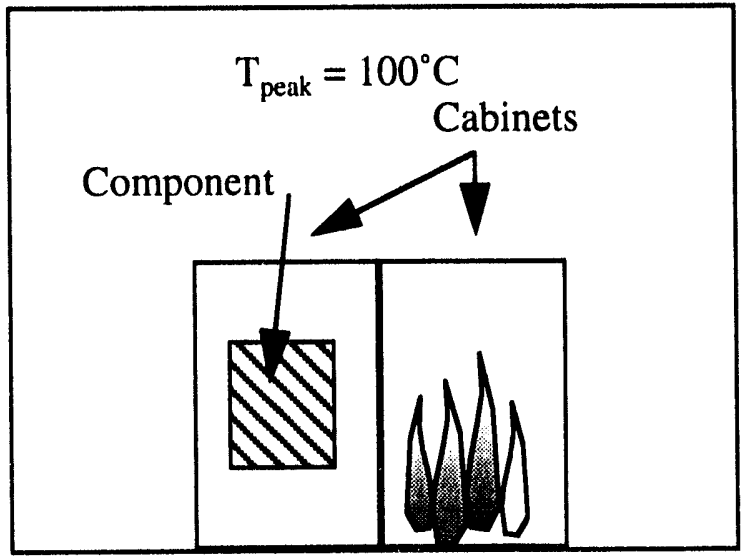

Component located in a cabinet adjacent to cabinet containing the fire source

Enclosure (room)

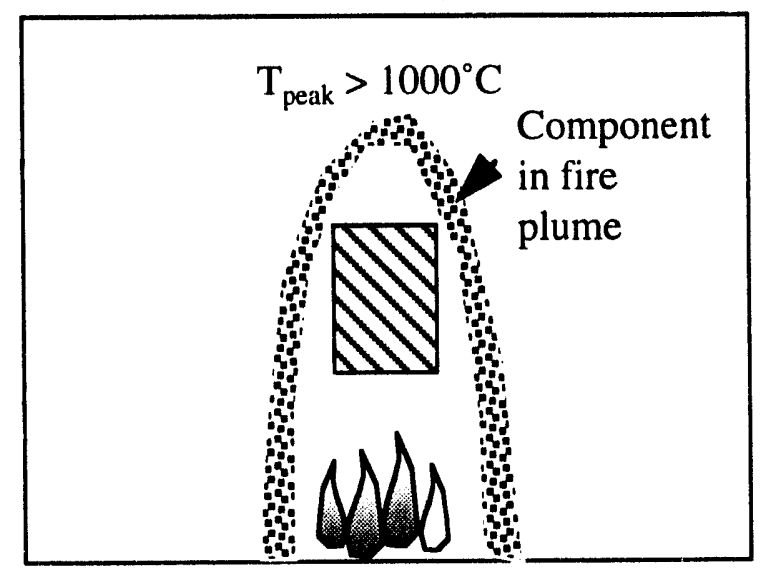

Component located directly in the fire plume

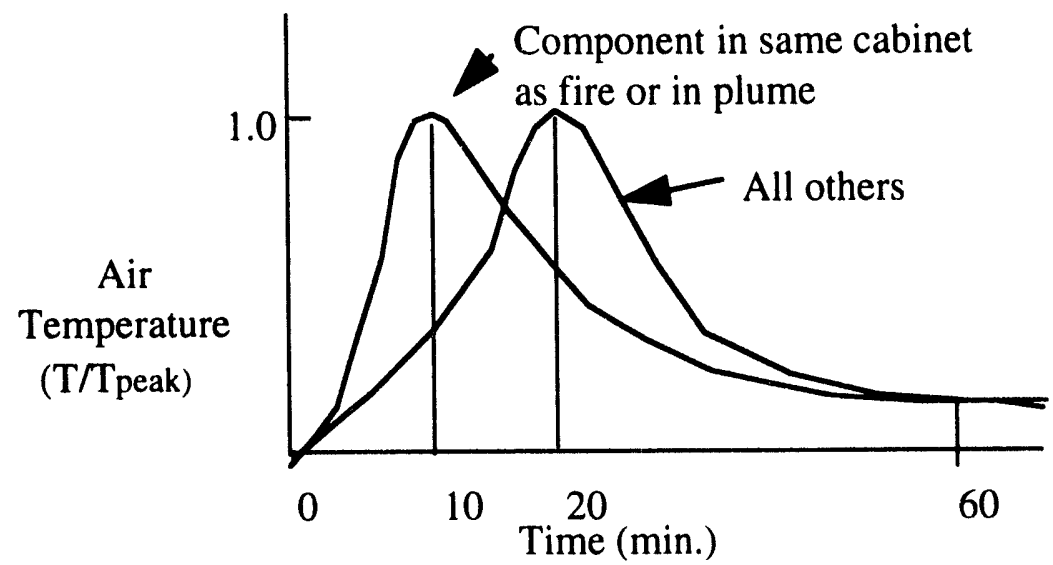

Figure 2. Generalized Fire-Induced Temperature Environments Resulting From Sandia Cabinet and Room Effects Tests. 
Table 1. Equipment summary ranking considering the impact of fire-induced damage on the functionality of the component (total list from Wanless [1]). Note that not all components will be included in the current study.

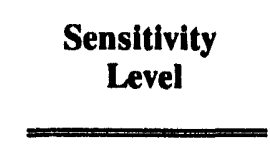

High

$$
\text { Equipment Type }
$$

Recorders

Logic Equipment

Controllers

Power Supplies

Meters

Solid State Relays

Electro Mechanical

Relays/Contactors

\section{Score}

.79

.77

.71

.67

.61

.60

.59

\begin{tabular}{|c|c|c|}
\hline Medium High & $\begin{array}{l}\text { Hand Switches/Pushbuttons } \\
\text { Transmitters (pressure, } \\
\text { temp., flow) } \\
\text { Battery Chargers/Inverters } \\
\text { Motor Control Centers } \\
\text { Switchgear } \\
\text { Batteries } \\
\text { Temperature Switches }\end{array}$ & $\begin{array}{l}.50 \\
.50 \\
.49 \\
.49 \\
.49 \\
.44 \\
.41\end{array}$ \\
\hline Medium Low & $\begin{array}{l}\text { Distribution Panels } \\
\text { Indicating Lights } \\
\text { Solenoid Valves } \\
\text { Thermocouples and RTDs } \\
\text { Non-Class 1E Cables* } \\
\text { Pressure Switches } \\
\text { Control Transformers } \\
\text { Motors (open)* } \\
\text { Position/Limit Switches } \\
\text { Power Transformers } \\
\text { Valve Positioners/Operators } \\
\text { Gauges } \\
\text { Terminal Blocks } \\
\text { Class 1E Cables* } \\
\text { Motors (enclosed)* }\end{array}$ & $\begin{array}{l}.38 \\
.37 \\
.34 \\
.33 \\
.33 \\
.33 \\
.29 \\
.28 \\
.26 \\
.26 \\
.25 \\
.20 \\
.18 \\
.17 \\
.17\end{array}$ \\
\hline Low & $\begin{array}{l}\text { Fans* } \\
\text { Heaters* } \\
\text { Valves* } \\
\text { Pumps* }\end{array}$ & $\begin{array}{l}.05 \\
.02 \\
.02 \\
.00\end{array}$ \\
\hline
\end{tabular}

- Components excluded from the current study. 
Table 2. Multipliers used to alter (increase) the predicted failure rates for control and support components when considering exposure to high temperature environmen $\div$ [2]. See Appendix 1 for a detailed listing of the IEEE Std. 500 data summarized here.

Component

\begin{tabular}{ll}
\hline \hline & \\
& \\
Instrumentation: & Shock \\
& Radiation \\
& Bistables \\
& Totalizers \\
& Power Supplies
\end{tabular}

Circuit Breakers, Interrupters, Relays

Transformers (instrumentation and power)

Annunciators

Valve Operators:

\section{Electric}

Pneumatic

Self Operated

Instrumentation: all other (see App. 1)
Multiplier

5.0

5.0

3.5

3.5

3.5

$1.26-2.55$

1.48-2.04

$1.30-2.00$

1.40-1.73

$1.45-1.67$

$1.35-1.40$

$1.00-2.00$ 
Table 3. Fraction of reported NPRDS component failures attributed to aging [4]. The numerator in each case is the total number of aging failures reported for the specific component during the surveyed time period (through 1986). The number of aging failures is also provided for comparison to the aging fraction. Ranking was based upon the aging fraction.

\begin{tabular}{|c|c|c|c|c|}
\hline Component & $\begin{array}{l}\text { Number of } \\
\text { Failures } \\
\text { (All Types) }\end{array}$ & $\begin{array}{c}\text { Number of } \\
\text { Aging Failures }\end{array}$ & Aging Fraction & \multirow[b]{2}{*}{ HIGH } \\
\hline $\begin{array}{l}\text { Annunciator } \\
\text { Instrumentation: } \\
\text { Isolation Device } \\
\text { Battery }\end{array}$ & $\begin{array}{c}6 \\
38 \\
246\end{array}$ & $\begin{array}{l}3 \\
17 \\
79\end{array}$ & $\begin{array}{l}0.50 \\
0.45 \\
0.32\end{array}$ & \\
\hline $\begin{array}{l}\text { Instrumentation: } \\
\text { Computation Module } \\
\text { Instrumentation: } \\
\text { Power Supply } \\
\text { Circuit Breaker } \\
\text { Valve Operator } \\
\text { Relay } \\
\text { Instrumentation: } \\
\text { Controller } \\
\text { Generator/Alternator/ } \\
\text { Inverter } \\
\text { Instrumentation: } \\
\text { Recorder }\end{array}$ & $\begin{array}{c}1104 \\
\\
315 \\
780 \\
2201 \\
587 \\
\\
433 \\
\\
459 \\
\\
649\end{array}$ & $\begin{array}{c}298 \\
\\
85 \\
203 \\
550 \\
147 \\
\\
104 \\
110 \\
\\
156\end{array}$ & $\begin{array}{l}0.27 \\
\\
0.27 \\
0.26 \\
0.25 \\
0.25 \\
\\
0.24 \\
0.24 \\
0.24\end{array}$ & MEDIUM \\
\hline $\begin{array}{l}\text { Transformer } \\
\text { Instrumentation: } \\
\text { Transmitter } \\
\text { Instrumentation: } \\
\text { Switch } \\
\text { Cables }\end{array}$ & $\begin{array}{c}31 \\
1911 \\
1609 \\
56\end{array}$ & $\begin{array}{c}5 \\
306 \\
225 \\
5\end{array}$ & $\begin{array}{l}0.16 \\
\\
0.16 \\
\\
0.14 \\
0.09\end{array}$ & \multirow[t]{2}{*}{ LOW } \\
\hline $\begin{array}{l}\text { al number of reported } \mathrm{f} \\
\text { al failures attributed to } \\
\text { al aging fraction: }\end{array}$ & $\begin{array}{l}\text { es for the } \\
\text { g: }\end{array}$ & nponents: & $\begin{array}{l}10425 \\
2308 \\
0.22\end{array}$ & \\
\hline
\end{tabular}

Systems considered in the above study (both PWR and BWR):

Class 1E power distribution

Component cooling water

Containment isolation

Low pressure injection

Reactor building cooling

Reactor protection trip

Residual heat removal

Standby liquid control
Auxiliary feedwater

Containment fan

High pressure injection

Main feedwater

Reactor core isolation cooling

Reactor coolant

Service water 
Table 4. Number of reported NPRDS component failures attributed to aging [4]. The total number of aging failures reported for the specific component during the surveyed time period (through 1986) is shown. Ranking is based upon the total number of aging failures.

\section{Component}

\begin{tabular}{l}
\hline Valve Operator \\
Instrumentation: \\
Transmitter \\
Instrumentation: \\
Computation Module \\
Instrumentation: \\
Switch \\
Circuit Breaker
\end{tabular}
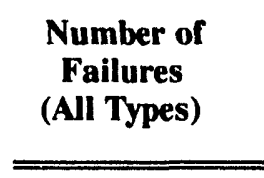

2201

1911

1104

1609

780
Number of
Aging Failures

550

306

298

225

203

Instrumentation:

Recorder

649

587

Generator/Alternator/

Inverter

Instrumentation:

Controller

Instrumentation:

Power Supply

Battery
459

433

315

246
156

147

110

104

85

79

Instrumentation:

Isolation Device

Transformer

Cables

Annunciator

38
31
56
6

6

Total failures attributed to aging:

Total aging fraction:

17

5 LOW

MEDIUM

HIGH

5

3

Systems considered in the above study (both PWR and BWR):

Class $1 \mathrm{E}$ power distribution

Component cooling water

Containment isolation

Low pressure injection

Reactor building cooling

Reactor protection trip

Residual heat removal

Standby liquid control
Auxiliary feedwater

Containment fan

High pressure injection

Main fecdwater

Reactor core isolation cooling

Reactor coolant

Service water 
Table 5. Total failures (age-related and otherwise) studied in the failure-cause analysis of Auxiliary Feedwater, Class 1E, High Pressure Injection, and Service Water Systems of a selected number of plants (Westinghouse, Babcock \& Wilcox)[4]

\begin{tabular}{|c|c|c|c|c|c|}
\hline Component & $\begin{array}{l}\text { Loss of } \\
\text { Sys Function* }\end{array}$ & $\begin{array}{l}\text { Loss of } \\
\text { Subs/Chan }\end{array}$ & $\begin{array}{l}\text { Loss of } \\
\text { Redundancy }\end{array}$ & $\begin{array}{l}\text { Degraded } \\
\text { Operation }\end{array}$ & $\begin{array}{l}\text { Sys Funct } \\
\text { Unafiected }\end{array}$ \\
\hline Battery & 0 & 2 & 0 & 1 & 7 \\
\hline Bus & 0 & 0 & 1 & 0 & 0 \\
\hline Charger & 0 & 8 & 11 & 11 & 5 \\
\hline Circuit breaker (AC) & 0 & 19 & 15 & 15 & 9 \\
\hline Controllers: All** & 0 & 32 & 19 & 11 & 12 \\
\hline Indicators: All** & 0 & 6 & 12 & 13 & 9 \\
\hline Inverter & 2 & 12 & 15 & 16 & 19 \\
\hline Power Supply & 0 & 0 & 1 & 0 & 0 \\
\hline Process Switches: All** & 0 & 5 & 14 & 21 & 19 \\
\hline Recorders: All** & 0 & 8 & 1 & 3 & 7 \\
\hline Relay & 0 & 9 & 3 & 5 & 1 \\
\hline Switches: All** & 0 & 1 & 2 & 3 & 1 \\
\hline Timer & 0 & 1 & 0 & 0 & 0 \\
\hline Transformer & 0 & 2 & 0 & 1 & 1 \\
\hline Transmitters: All** & 0 & 38 & 15 & 13 & 43 \\
\hline Valves: Motor \& Pneu & ed 1 & 111 & 47 & 140 & 128 \\
\hline Valves: Solenoid Operate & 0 & 0 & 3 & 1 & 0 \\
\hline
\end{tabular}

- Definitions of severity levels (greatest severity first):

Loss of System Function - A component failure which, by itself, results

Loss of Subsystem/Channel - A partial loss of system functional path.

Loss of Redundancy - Loss of one system functional path.

Degraded System Operation - The system is capable of fulfion Unaffected - Failure did not affect the operation of the system.

* For further breakdown of these groups see Table A2 in the Appendix.

Solenoid valves are listed separately from mor and pneute failures

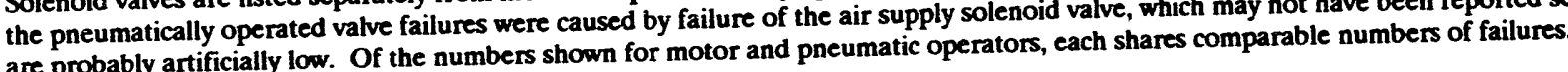


Table 6. Total failures from failure cause results in Table 5 ordered by the number of failures which affected system operation (Significant Failures). This figure is the sum of all failures for a given component excluding those classified as not affecting system operation. Also shown is the ratio of failures impacting operation to the total number of failures reported for that component ("Significant Failure" fraction).

\begin{tabular}{|c|c|c|c|}
\hline Component & $\begin{array}{c}\text { Significant } \\
\text { Failure } \\
\text { Fraction }\end{array}$ & $\begin{array}{r}\text { Signific } \\
\text { Failur } \\
\text { (Failu } \\
\text { impacting } \\
\text { operati }\end{array}$ & $\begin{array}{l}\text { ant } \\
\text { es } \\
\text { es } \\
\text { ystem } \\
\text { on) }\end{array}$ \\
\hline $\begin{array}{l}\text { Valves: Motor \& Pneumatically Operated } \\
\text { Transmitters } \\
\text { Controllers } \\
\text { Circuit Breaker (AC) } \\
\text { Inverter } \\
\text { Process Switches }\end{array}$ & $\begin{array}{l}.70 \\
.61 \\
.84 \\
.84 \\
.70 \\
.68\end{array}$ & $\begin{array}{l}299^{*} \\
66 \\
62 \\
49 \\
45^{* *} \\
40\end{array}$ & High \\
\hline $\begin{array}{l}\text { Indicators } \\
\text { Charger } \\
\text { Relay } \\
\text { Recorders }\end{array}$ & $\begin{array}{l}.77 \\
.85 \\
.94 \\
.63\end{array}$ & $\begin{array}{l}31 \\
29 \\
17 \\
12\end{array}$ & Medium \\
\hline $\begin{array}{l}\text { Switches } \\
\text { Valves: Solenoid Operated } \\
\text { Transformer } \\
\text { Battery } \\
\text { Bus } \\
\text { Power Supply } \\
\text { Timer }\end{array}$ & $\begin{array}{l}.86 \\
1.00 \\
.75 \\
.30 \\
.00 \\
1.00 \\
1.00\end{array}$ & $\begin{array}{l}6 \\
4 \\
3 \\
3 \\
1 \\
1 \\
1\end{array}$ & Low \\
\hline
\end{tabular}

\footnotetext{
- One of these failures caused complete loss of system function.

* Two of these failures caused complete loss of system function.
} 
Table 7. Component group with the highest overall ranking with respect to fire susceptibility and potential for degradation of plant system operations. Components were then ranked according to aging fraction and aging failures.

$$
\text { Aging Susceptibility } 1
$$

\section{Aging Aging}

Fraction Failure

Component

Instrument:

Computation Module Medium High

Circuit Breaker Medium High

Instrument:

Isolation Device

Recorder

Logic Equipment

Controllers

Solid State Relays

Electromechanical Relays/Actuators

Transmitters

Temperature Switches

Meters

\section{Fire Sesceptibility 5}

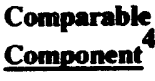

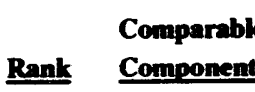

Instrument Switch

(non-specific)

Instrumentation Switch
High

Hign

High

High

High

High

High

High

High

Medium

Medium

Controller, Logic Equipment

Electromechanical Relay

Controller

High
Impact on Plant Operation 7

Rank Component

High Transmitter, Controller

High

High

Transmitter, Controller

Medium Indicator

High Controlier

High

Medium Relay (non-specific)

Medium Relay (non-specific)

High

High Process Switch

(non-specific)

Medium Indicator

Notes:

1. From Tables 3 and 4 ranking.

2. From Table 3 ranking.

3. From Table 4 ranking.

4. If the component was not explicitly addressed in Table 3 and 4 , a component of similar aging characteristic was used to rank.

5. From Table 1 ranking.

6. If the component was not explicitly addressed in Table 1 , a component of similar fire suspectibility was used to rank.

7. From Table 6 ranking.

8. If the component was not explicitly addressed in Table 6, a component of similar plant safety function was used to rank. 
Table 8. Component group with the intermediate overall ranking with respect to fire susceptibility and potential for degradation of plant system operations. Components were then ranked according to aging fraction and aging failures.

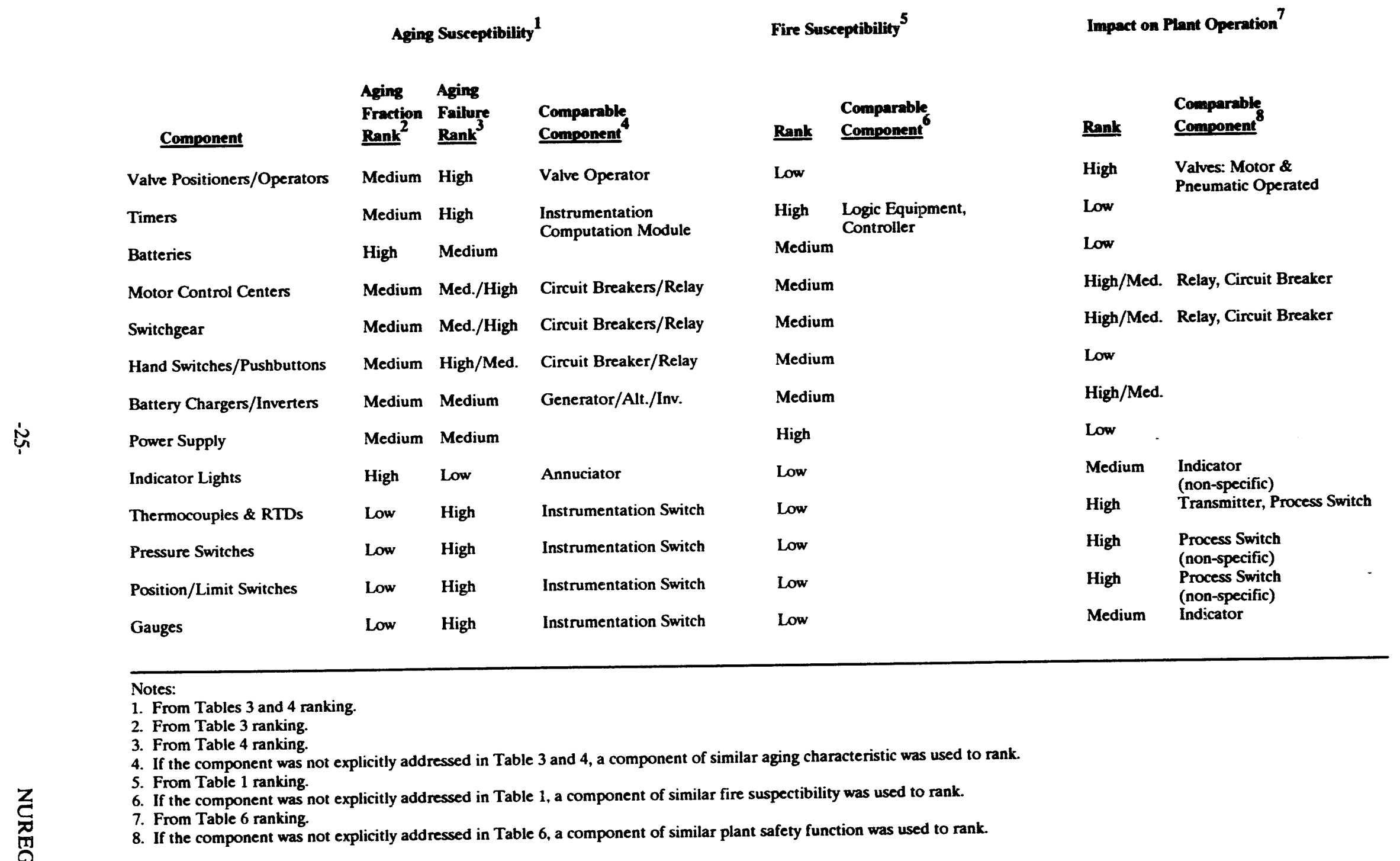


Table 9. Component group with the lowest overall ranking with respect to fire susceptibility and potential for degradation of plant system operations. Components were then ranked according to aging fraction and aging failures.

Aging Susceptibility 1

Aging Aging

$\begin{array}{lll}\text { Fraction } & \text { Failure } & \text { Comparable } \\ \text { Rank }^{2} & \text { Rank } & \text { Component }\end{array}$

Component

Solenoid Valves

Distribution Panels

Control Transformers

Power Transformers

Terminal Blocks

Bus
Medium High

Low Low

Low Low

Low

Low

Low Low

Low Low

Cables

Transformers

(non-specific)

Transformers

(non-specific)

Cables $^{9}$
Fire Susceptibility 5

Valve Operator

Terminal Blocks, Cables

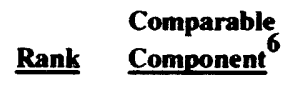

Low

Low

Low

Low

Low

Low
Impact on Plant Operation ${ }^{7}$

$\begin{array}{ll}\text { Rank } & \begin{array}{l}\text { Comparable } \\ \text { Component }\end{array} \\ \text { Low } & \\ \text { Low } & \text { Bus } \\ \text { Low } & \\ \text { Low } & \begin{array}{l}\text { Transformers } \\ \text { (non-specific) }\end{array} \\ \text { Low } & \text { Bus }\end{array}$

Low

Notes:

1. From Tables 3 and 4 ranking.

2. From Table 3 ranking.

3. From Table 4 ranking.

4. If the component was not explicitly addressed in Table 3 and 4 , a component of similar aging characteristic was used to rank.

5. From Table 1 ranking.
6 . If the component was not explicitly addressed in Table 1 , a component of similar fire suspectibility was used to rank.

7. From Table 6 ranking.

8. If the component was not explicitly addressed in Table 6, a component of similar plant safety function was used to rank.

8. If the component was not explicitly addressed in Table 6, a component of similar plant safety function
9 Although terminal blocks and cables are physically different, their intended functions are similar. 
Table 10. High priority component survey results.

\begin{tabular}{|c|c|c|c|c|}
\hline Component & $\begin{array}{l}\text { Manufacturer \& } \\
\text { Model Number }\end{array}$ & $\begin{array}{l}\text { \% of Total } \\
\text { Population }\end{array}$ & $\begin{array}{l}\text { Total } \\
\text { Population }\end{array}$ & $\begin{array}{l}\text { Average } \\
\text { per Plant }\end{array}$ \\
\hline Relays & $\begin{array}{c}\text { GE HMA } \\
\text { GE HFA } \\
\text { GE HGA }\end{array}$ & $\begin{array}{r}7 \\
21 \\
12\end{array}$ & 13244 & 697 \\
\hline Circuit Breakers & ITE HE3-BXXX & 6 & 7048 & 371 \\
\hline Recorders & Leeds \& Northrup 134 & 8.5 & 341 & 18 \\
\hline Meters & GE 180 & 27 & 199 & 11 \\
\hline Computation Modules & $\begin{array}{c}\text { Sorrento RM23 } \\
\text { Sorrento RM20 }\end{array}$ & $\begin{array}{l}15.5 \\
15.5\end{array}$ & 129 & 7 \\
\hline Isolation Devices & Consolidated Controls ${ }^{*}$ & 76 & 3288 & 173 \\
\hline Controllers & Thermoelectric 3230311012-SP & 40 & 603 & 32 \\
\hline Transmitter & Rosemount 1153 (level) & 15 & 1687 & 89 \\
\hline
\end{tabular}


Table 11. Intermediate priority component survey results.

\begin{tabular}{|c|c|c|c|c|}
\hline Component & $\begin{array}{l}\text { Manufacturer \& } \\
\text { Model Number }\end{array}$ & $\begin{array}{l}\text { \% of Total } \\
\text { Population }\end{array}$ & $\begin{array}{l}\text { Total } \\
\text { Population }\end{array}$ & $\begin{array}{l}\text { Average } \\
\text { per Plant }\end{array}$ \\
\hline $\begin{array}{l}\text { Thermocouples \& } \mathrm{Th} \\
\text { RTDs }\end{array}$ & $\begin{array}{l}\text { hermoelectric T18UNG304140L } \\
\text { Weed N9004E and N9004S } \\
\text { Pyco 102-9039-08-6 }\end{array}$ & $\begin{array}{r}22 \\
18 \\
4\end{array}$ & 1094 & 56 \\
\hline Switches & $\begin{array}{c}\text { GE SBM (control) } \\
\text { GE CR2940 (manual) } \\
\text { Microswitch PTS (manual) } \\
\text { NAMCO EA180 (limit) }\end{array}$ & $\begin{array}{r}11 \\
6 \\
4 \\
3\end{array}$ & 7586 & 399 \\
\hline Switchgear & GE Magnablast & 30 & 145 & 7 \\
\hline Motor Control Centers & GE 7700 & 33 & 96 & 5 \\
\hline $\begin{array}{l}\text { Battery Chargers \& } \\
\text { Inverters }\end{array}$ & $\begin{array}{l}\text { Exide UPC-130-3-400 } \\
\text { Topaz Electronics } 5352-13\end{array}$ & $\begin{array}{r}10 \\
12.5\end{array}$ & $\begin{array}{r}117 \\
96\end{array}$ & $\begin{array}{l}6 \\
5\end{array}$ \\
\hline Indicator Lights & GE ET-16 & 60 & 466 & 25 \\
\hline Timers & Agastat E7000 & 72 & 612 & 32 \\
\hline Batteries & $\begin{array}{l}\text { C \& D LCR-25 (cell) } \\
\text { GNB NCX-9 (unit) }\end{array}$ & $\begin{array}{c}34 \\
2\end{array}$ & 467 & 25 \\
\hline Power Supplies & GE 236X185G1 & 30 & 399 & 21 \\
\hline $\begin{array}{l}\text { Valve Positioner \& } \\
\text { Operators/Actuators }\end{array}$ & Fisher $^{*}$ & 15 & 771 & 41 \\
\hline Solenoid Valves & ASCO NP8320 & 10 & 1267 & 67 \\
\hline
\end{tabular}

- No model number listed. 
Table 12. Generalized peak fire-induced air temperature environments for components, based on Sandia cabinet and room effects tests. Refer to Figure 2 for a description of each peak temperature environment.

\section{Credible Peak Air Temperature}

\section{Equipment Type}

\begin{tabular}{l}
\hline Recorders \\
Controllers \\
Meters \\
Hand Switches/Pushbuttons \\
Indicating Lights
\end{tabular}

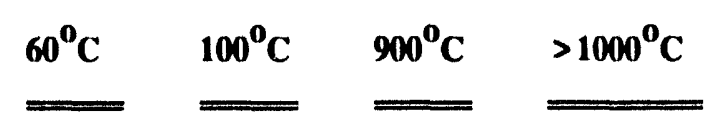

\begin{tabular}{|c|c|c|c|c|c|}
\hline $\begin{array}{l}\text { Logic Equipment } \\
\text { Power Supplies } \\
\text { Solid State Relays } \\
\text { Electro Mechanical } \\
\text { Relays/Contactors } \\
\text { Control Transformers } \\
\text { Terminal Blocks }\end{array}$ & * & $\begin{array}{l} \\
* \\
* \\
* \\
* \\
*\end{array}$ & $\begin{array}{l}\text { * } \\
* \\
* \\
* \\
* \\
*\end{array}$ & & $\begin{array}{l}\text { Normally } \\
\text { enclosed in } \\
\text { a cabinet. }\end{array}$ \\
\hline $\begin{array}{l}\text { Transmitters (pressure, } \\
\text { temp., flow) }\end{array}$ & * & & & * & \\
\hline Battery Chargers/Inverters & * & & & * & Stand-alone \\
\hline Motor Control Centers & * & & & * & component \\
\hline Switchgear & * & & & $*$ & (exposed to \\
\hline Batteries & * & & & $*$ & room air), \\
\hline Temperature Switches & * & & & * & possibly \\
\hline Distribution Panels & $*$ & & $*$ & $*$ & exposed \\
\hline Solenoid Valves & * & & & * & directly to \\
\hline Thermocouples and RTDs & * & & & $*$ & fire plume. \\
\hline Pressure Switches & * & & & * & \\
\hline Position/Limit Switches & * & & & * & \\
\hline Power Transformers & * & & & * & \\
\hline Valve Positioners/Operators & * & & & * & \\
\hline Gauges & * & & & * & \\
\hline
\end{tabular}


Table 13. Proposed general test requirements for the high priority components list.

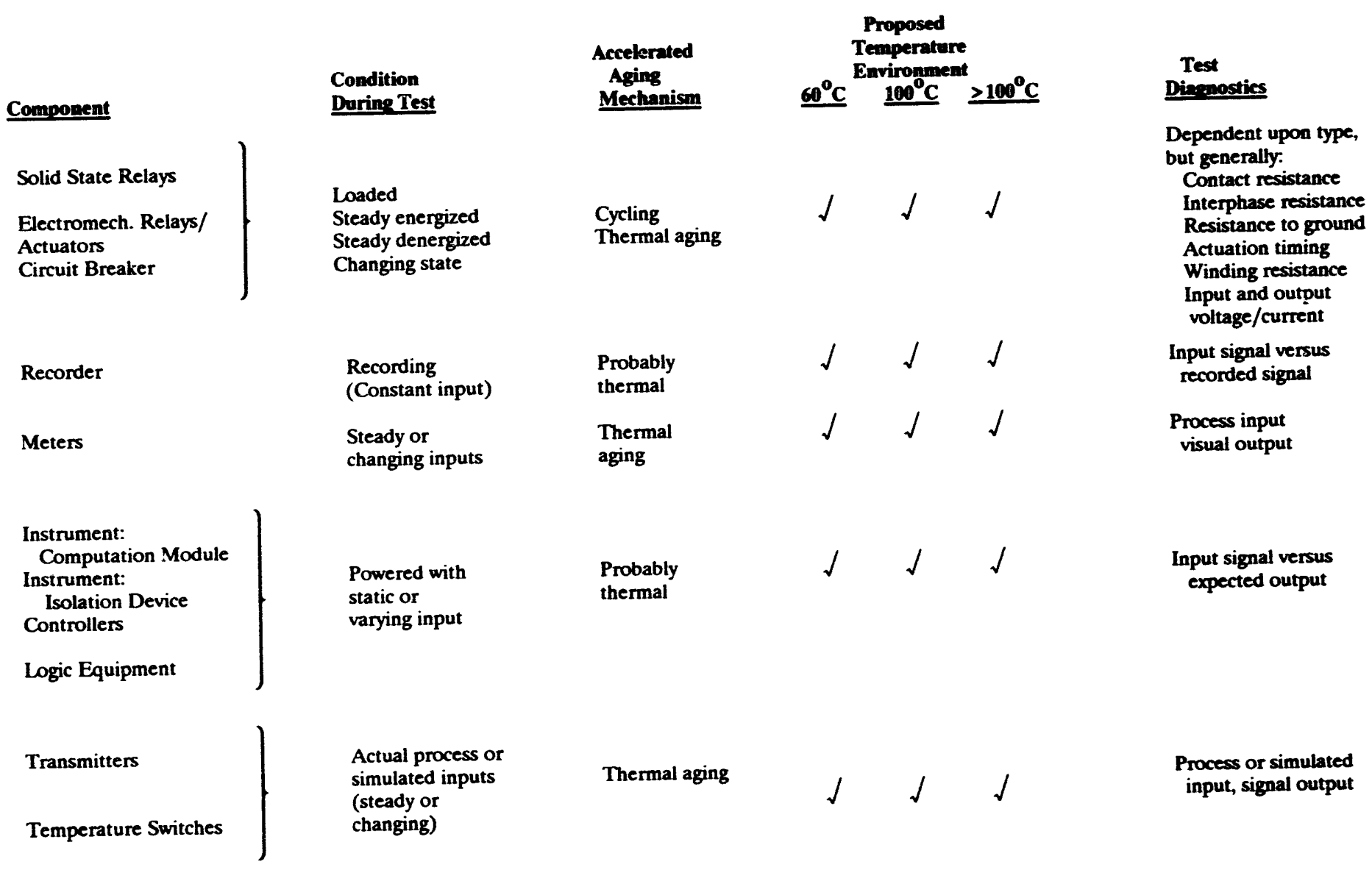


Table 14. Proposed general test requirements for the intermediate priority components list.

\begin{tabular}{|c|c|c|c|c|c|c|}
\hline Component & $\begin{array}{l}\text { Condition } \\
\text { Durine Test }\end{array}$ & $\begin{array}{l}\text { Accelerated } \\
\text { Aging } \\
\text { Mechanism }\end{array}$ & $60^{\circ} \mathrm{C}$ & $\begin{array}{l}\text { Proposed } \\
\text { Temperature } \\
\text { Environment } \\
100^{\circ} \mathrm{C} \geq\end{array}$ & $\geq 100^{\circ} \mathrm{C}$ & $\begin{array}{l}\text { Test } \\
\text { Dinerposties }\end{array}$ \\
\hline $\begin{array}{l}\text { Thermocouples } \\
\text { and RTDs } \\
\text { Pressure Switches }\end{array}$ & $\begin{array}{l}\text { Actual process or } \\
\text { simulated inputs } \\
\text { (steady or } \\
\text { changing) }\end{array}$ & Thermal aging & $\sqrt{ }$ & $\sqrt{ }$ & $\sqrt{ }$ & $\begin{array}{l}\text { Process or simulated } \\
\text { input, signal output }\end{array}$ \\
\hline Motor Control Centers & \multicolumn{2}{|c|}{$\begin{array}{l}\text { Test subcomponents individually } \\
\text { (relays, CBs, etc.) }\end{array}$} & $J$ & $\checkmark$ & & $\begin{array}{l}\text { See individual } \\
\text { components }\end{array}$ \\
\hline Battery Chargers/Inverters & $\begin{array}{l}\text { Loaded } \\
\text { (Charging/inverting) }\end{array}$ & Thermal aging & $\sqrt{ }$ & $\sqrt{ }$ & $\sqrt{ }$ & $\begin{array}{l}\text { Input and output } \\
\text { voltage/current }\end{array}$ \\
\hline Switchgear & Loaded/Changing state & $\begin{array}{l}\text { Cycling } \\
\text { Thermal aging }\end{array}$ & $\sqrt{ }$ & $\sqrt{ }$ & $\sqrt{ }$ & \\
\hline Position/Limit Switches & $\begin{array}{l}\text { Steady or changing } \\
\text { position }\end{array}$ & $\begin{array}{l}\text { Thermal aging } \\
\text { Cycling }\end{array}$ & $\sqrt{ }$ & $\sqrt{ }$ & $\sqrt{ }$ & $\begin{array}{c}\text { Input position, } \\
\text { signal output }\end{array}$ \\
\hline $\begin{array}{l}\text { Indicator Lights } \\
\text { Gauges }\end{array}$ & $\begin{array}{l}\text { Steady or } \\
\text { changing inputs }\end{array}$ & Thermal aging & $J$ & $J$ & $\sqrt{ }$ & $\begin{array}{l}\text { Process input } \\
\text { visual output }\end{array}$ \\
\hline Timers & Timing & $\begin{array}{l}\text { Probably } \\
\text { thermai }\end{array}$ & $J$ & $\sqrt{ }$ & & $\begin{array}{l}\text { Repetitive timing } \\
\text { check during test }\end{array}$ \\
\hline Batteries & $\begin{array}{l}\text { Charging and } \\
\text { discharging }\end{array}$ & $\begin{array}{l}\text { Probably } \\
\text { thermal }\end{array}$ & $\sqrt{ }$ & $\sqrt{ }$ & $\sqrt{ }$ & $\begin{array}{l}\text { Voltage, current output } \\
\text { characteristies }\end{array}$ \\
\hline Power Supplies & $\begin{array}{l}\text { Steady-state } \\
\text { loaded }\end{array}$ & Thermal aging & $\sqrt{ }$ & $J$ & $J$ & $\begin{array}{l}\text { Voltage, current output } \\
\text { characteristics }\end{array}$ \\
\hline $\begin{array}{l}\text { Valve Positioners } \\
\text { /Operators } \\
\text { Solenoid Valves }\end{array}$ & Changing position & $\begin{array}{l}\text { Cycling } \\
\text { Thermal aging }\end{array}$ & $\sqrt{ }$ & $\downarrow$ & $J$ & Input signal versus \\
\hline $\begin{array}{l}\text { Hand Switches } \\
\text { /Pushbuttons }\end{array}$ & $\begin{array}{l}\text { Static } \\
\text { Changing positions }\end{array}$ & $\begin{array}{l}\text { Cycling } \\
\text { Thermal aging }\end{array}$ & $\sqrt{ }$ & $J$ & $J$ & $\begin{array}{l}\text { Input position, signal } \\
\text { output }\end{array}$ \\
\hline
\end{tabular}




\section{APPENDIX A \\ Supplementary Information}

\section{IEEE Std. 500 High Temperature Environmental Multipliers}

The multipliers listed below are extracted from IEEE Std. 500, "IEEE Guide to the Collection and Presentation of Electrical, Electronic, Sensing Component, and Mechanical Equipment Reliability Data for Nuclear-Power Generating Stations" [2]. The bulk of the Guide is reliability data for components (in the form of failures per plant-year). In the process of assembling the data, however, the editors obtained opinions of knowledgeable individuals to provide environmental multipliers for certain conditions (high temperature, humidity, radiation). These multipliers represent the degree to which the condition would decrease component reliability. This is not as quantitative as the method used by Wanless [1] but covers many more specific components and is used in the body of this report to support the prioritization of components when considering susceptibility to elevated temperatures. The rationale for the factors were not provided in the reference so the numbers are assumed to be subjective. The lists of individual components and factors follow in Table A1. 
Table A1. High temperature environmental multipliers [2].

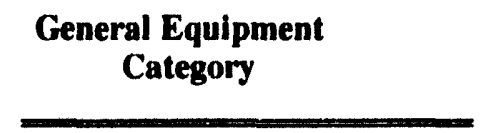

Annunciator Modules:

Batteries, Chargers and Voltage Regulators:

Circuit Breakers,

Interrupters, and

Relays:

Transformers:

Valve Operators and Actuators:

\section{Specific Component}

Alarm - solid state visual

Alarm - relay

Alarm - isolating

Alarm - indicator

Bell

Buzzer

Klaxon

Horn

Gong

Siren

Battery Charger Rectifier -SCR magnetic amplifier

Battery Charger Rectifier - SCR

Secondary Battery - lead acid

Secondary Battery - jelly

electrolyte

Secondary Battery - Ni Cad

Circuit Brcaker - all

Relay - armature

Relay - crystal can

Relay - latching

Controller

Starter

Contactor

Switch - control

Switch - power

Fuse

All (big) station types

Instrumentation - potential

Instrumentation - current

Electrical - motor operated

Electrical - solenoid operated

Pneumatic

Self Operated
High

Temperature Multiplier

1.50

2.00

1.50

2.00

1.50

2.00

1.30

1.50

1.40

2.00

1.40

1.50

1.50

1.50

1.40

$2.19^{*}$

1.45

1.26

1.30

2.07

2.13

2.13

1.92

1.46

1.46

$1.48-1.82$

1.59

2.04

1.40

1.73

$1.45-1.67$

$1.35-1.40$

No breakdown as to circuit breaker type was provided. 
Table A1 (cont'd). High temperature environmental multipliers [2].

\section{General Equipment \\ Category}

Instruments, Controls, and Sensors:

\section{Specific Component}

Temperature - transducer

Temperature - transmitter

Temperature - process switch

Pressure - transducer

Pressure - process switch

Flow/Velocity - transducer

Flow/Velocity - transmitter

Flow/Velocity - process switch

Level - transmitter

Level - process switch

Level - controller

Level - float

Speed - transducer

Speed - centrifugal switch

Vibration

Shock

Displacement

Radiation

Seismic

Humidity

Meteorology

Power Transducer

Water Chemistry

Signal Modifier

Bistable

Indicating Controllers

Totalizer

Indicator

Recorder

Power Supply
High

Temperature

Multipller

1.00

2.00

1.50

2.00

1.50

1.67

2.00

1.50

2.00

1.10

1.50

2.00

1.50

1.50

1.20

5.00

1.50

5.00

1.00

1.50

2.00

1.20

2.00

2.00

3.50

1.25

3.50

1.60

2.00

3.50 
Table A2. Total age-related failures studied in Auxiliary Feedwater, Class 1E, High Pressure Injection, and Service Water Systems of a selected number of plants (Westinghouse, Babcock \& Wilcox)[4]. This list includes a breakdown of several groups that were summarized in Table 5 of the main text.

\begin{tabular}{|c|c|c|c|c|c|}
\hline Component & $\begin{array}{l}\text { Loss of } \\
\text { Sys Funct }\end{array}$ & $\begin{array}{c}\text { Loss of } \\
\text { Subs/Chan }\end{array}$ & $\begin{array}{c}\text { Loss of } \\
\text { Redundancy }\end{array}$ & $\begin{array}{l}\text { Degraded } \\
\text { Operation }\end{array}$ & $\begin{array}{l}\text { Sys Funct } \\
\text { Unaffected }\end{array}$ \\
\hline Battery & 0 & 2 & 0 & 1 & 7 \\
\hline Bus & 0 & 0 & 1 & 0 & 0 \\
\hline Charger & 0 & 8 & 11 & 11 & 5 \\
\hline Circuit breaker (AC) & 0 & 19 & 15 & 15 & 9 \\
\hline Controller: Diff. Pressure & 0 & 6 & 1 & 0 & 1 \\
\hline Controller: Flow & 0 & 11 & 4 & 1 & 4 \\
\hline Controller: Level & 0 & 7 & 8 & 7 & 3 \\
\hline Controller: load Sequence & 0 & 3 & 4 & 1 & 2 \\
\hline Controller: Pressure & 0 & 4 & 1 & 2 & 2 \\
\hline Controller: Speed & 0 & 0 & 1 & 0 & 0 \\
\hline Controller: Unspecified & 0 & 1 & 0 & 0 & 0 \\
\hline Indicator: Current Control & 0 & 1 & 0 & 0 & 0 \\
\hline Indicator: Flow & 0 & 0 & 1 & 2 & 0 \\
\hline Indicator: Flow Control & 0 & 1 & 0 & 0 & 3 \\
\hline Indicator: Flow Switch & 0 & 0 & 2 & 0 & 0 \\
\hline Indicator: Level Control & 0 & 1 & 9 & 10 & 0 \\
\hline Indicator: pressure & 0 & 3 & 0 & 0 & 3 \\
\hline Indicator: Temperature & 0 & 0 & 0 & 0 & 3 \\
\hline Indicator: Temperature Control & 0 & 0 & 0 & 1 & 0 \\
\hline Inverter & 2 & 12 & 15 & 16 & 19 \\
\hline Power Supply & 0 & 0 & 1 & 0 & 0 \\
\hline Process Switch: Current & 0 & 0 & 0 & 0 & 1 \\
\hline Process Switch: Flow & 0 & 1 & 2 & 5 & 10 \\
\hline Process Switch: Level & 0 & 0 & 0 & 1 & 2 \\
\hline Process Switch: Pressure & 0 & 2 & 12 & 15 & 2 \\
\hline Process Switch: Temperaturc & 0 & 2 & 0 & 0 & 4 \\
\hline Recorder: Flow Control & 0 & 5 & 0 & 1 & 4 \\
\hline Recorder: Level & 0 & 1 & 0 & 1 & 1 \\
\hline Recorder: Pressure Control & 0 & 2 & 1 & 1 & 2 \\
\hline Relay & 0 & 9 & 3 & 5 & 1 \\
\hline Switch: hand & 0 & 1 & 2 & 1 & 0 \\
\hline Switch: position limit & 0 & 0 & 0 & 0 & 1 \\
\hline Switch: unspecified & 0 & 0 & 0 & 2 & 0 \\
\hline Timer & 0 & 1 & 0 & 0 & 0 \\
\hline Transformer & 0 & 2 & 0 & 1 & 1 \\
\hline Transmitter: Flow & 0 & 21 & 6 & 0 & 15 \\
\hline Transmitter: Level & 0 & 10 & 7 & 4 & 23 \\
\hline Transmitter: Pressurc & 0 & 7 & 2 & 9 & 5 \\
\hline Valve: Motor Operated & 1 & 57 & 35 & 73 & 102 \\
\hline Valve: Pneumatically Operated & 0 & 54 & 12 & 67 & 26 \\
\hline Valve: Solenoid & 0 & 0 & 3 & 1 & 0 \\
\hline
\end{tabular}


DISTRIBUTION:

U. S. Government Printing Office Receiving Branch (Attn: NRC Stock)

8610 Cherry Ln. Laurel, MD 20707

(200 copies for RP Distribution)

U. S. Nuclear Regulatory Commission

Division of Engineering

Attn: C. Antonescu

5650 Nicholson Ln.

Rockville, MD 20852

( 5 copies)

U. S. Nuclear Regulatory Commission

Regulatery Applications Branch

Attn: J. Flack

5650 Nicholson Ln.

Rockville, MD 20852

U. S. Nuclear Regulatory Commission Electrical Engineering Branch

Attn: A. Datta

5650 Nicholson Ln.

Rockville, MD 20852

U. S Department of Energy

Attn: C. Caves

W. Maybee

Mail Stop EG-34

Washington, DC 20545

U. S. Department of Energy

Attn: J. Zamirowski

9800 S. Cass Av.

Argonne, IL 60439

U. S. Department of the Navy

Attn: M. Matteson

Mail Code 1740.2

David M. Taylor Naval Ship

Research and Development Center

Bethesda, MD 20084-5000

U. S. Department of the Navy

Attn: D. Satterfield

National Center \#4, Room 311

Naval Sea System Command (56Y52)

Washington, DC 20362

Lawrence Livermore National Laboratory

Attn: H. Hasegawa

Mail Stop L-442

P O Box 5505

Livermore, CA 94550
Brookhaven National Laboratories

Attn: J. Boccio

Bldg. 130

Upton, NY 11793

Impell Corp.

Attn: S. Chingo

300 Tri-State International

Suite $\mathbf{3 0 0}$

Lincolnshire, IL 60015

Impell Corp.

Attn: C. Lewis

J. Echternacht

350 Lennon Ln.

Walnut Creek, CA 94598

Professional Loss Control

Attn: K. Dungan

P O Box 446

Oak Ridge, TN 37830

Electric Power Research Institute

Attn: J. Sursock

Nuclear Power Division

3412 Hillview Av.

Palo Alto, CA 94303

American Nuclear Insurers

Attn: D. Sherman, Library

Exchange Building, Suite 245

270 Farmington Av.

Farmington, CT 06032

Underwriters Laboratories

Attn: L. Przybyla

333 Pfingston Rd.

Northbrook, IL 60062

Patton Fire Suppression Systems

Attn: R. Patton

5316 Roseville Rd., Suite $P$

North Highlands, CA 95660

Factory Mutual Research Corp.

Attn: J. Newman

1151 Boston-Providence Hwy.

Norwood, MA 02062

American Electric Power Service Corp.

Attn: J. Grier

Mechanical Engineering Division

19th Floor

P O Box 16631

Columbus, $\mathrm{OH} 43216$ 
Grinnell Fire Protection Co.

Attn: J. Priest

10 Dorrance St.

Providence, RI 02903

Edison Electric Institute

Attn: J. Evans

111 19th St., NW

Washington, DC 20036-3691

Wisconsin Electric Power Co.

Attn: M. Kaminski

Fire Protection Officer, A-543

333 W. Everett St.

Milwaukee, WI 53203

Arkansas Power and Light

Attn: R. Rospoli

1312 N. Nashville St.

Russelville, AR 72801

Gesamthoshschule Kassel

Attn: Ulrich Heinze Schneider

Universitat das Landes Hessen

FB 14, Postfach 101380

3500 Kassel

Federal Republic of Germany

Koning and Heunisch

Attn: Dietmar Hosser

Lezter Hasenpfach 21

6000 Frankfurt/ Main 70

Federal Republic of Germany

Geselschaft fur Reaktorsicherheit

Attn: Mr. Liemersdorf

Scwertnergasse 1

D-5000 Koln 1

Federal Republic of Germany

Centre Scientifique et Technique du Batiment

Attn: Xavier Bodart

Station de Recherche

84 Avenue Jean-Jaures-Champs-sur-Marne

77428 Marne-La-Valle Cedex 2

France

Societe Bertin \& Cie

Attn: Serge Galant

BP No. 3

78373 Plaisir Cedex

France
Electricite de France

Attn: Jean-Pierre Berthet

Thermal Production Headquarters

EDF-DSRE-6, Rue Ampere

BP 114

93203 Saint Denis Cedex 1

France

HM Nuclear Installations Inspectorate

Attn: Paul Woodhouse

St. Peters House

Stanley District

Balliol Road

Bootle

Merseyside L20 3LZ

England

NUPEC

Attn: Kenji Takumi

No. 2 Akiyama Building

6-2, 3-Chome, Toranomon

Minatoku, Toyko 105, Japan

Science \& Engineering Associates, Inc.

Attn: W. Lowry

1570 Pacheco St. Suite D-1

Santa Fe, NM 87501

( 5 copies)

Internal SNL:

6400 N. Ortiz

6403 W. von Riesemann

6449 M. Bohn

6449 S. Nowlen

6449 T. Tanaka

6449 R. Vigil (25)

8523-2 Central Technical Files

7141 Technical Library (5)

7151 Technical Publications 
ISee instructions on the reverse)

NUREG/CR-6103

SAND93-710\%

2. TITLE ANOD SUBTITLE

Prioritization of Reactor Control Components

Susceptible to Fire Damage as a Consequence

of Aging

5. AUTHOR(S)

W. Lowry, R. Virgil/SEA

S. Nowlen/Sandia Project Monitor

DATE REPORT PUB_ISMEZ

Morir

January

1994

4. FIN OR GRANT NUMBEF

A1833

6. TYPE OF REPORT

Technical

7. PERIOD COVEREO Unciusue O०.t.

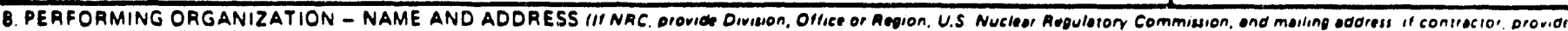
neme ond moiling odomss!

Science and Engineering Associates, Inc.

Under Contract to:

6100 Uptown Blvd.

Sandia National Laboratories

Albuquerque, NM 87110

Albuquerque, NM 87185

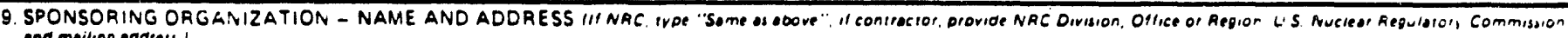

ond mailing nooress.

Division of Engineering

Office of Nuclear Regulatory Research

U.S. Nuclear Regulatory Commission

Washington, DC 20555-0001

10 SUPPLEMENTARY NOTES

11. ABSTRACT 1200 woros or iess,

The Fire Vulnerability of Aged Electrical Components Test Program is to identify and assess issues of plant aging that could lead to an increase in nuclear power plant risk because of fires. Historical component data and prior analyses are used to prioritize a list of components with respect to aging and fire vulnerability and the consequences of their failure on plant safety systems. The component list emphasizes safety system control components, but excludes cables, large equipment, and devices encompassed in the Equipment Qualification (EQ) program. The test program selected components identified in a utility survey and developed test and fire conditions necessary to maximize the effectiveness of the test program. Fire damage considerations were limited to purely thermal effects. 

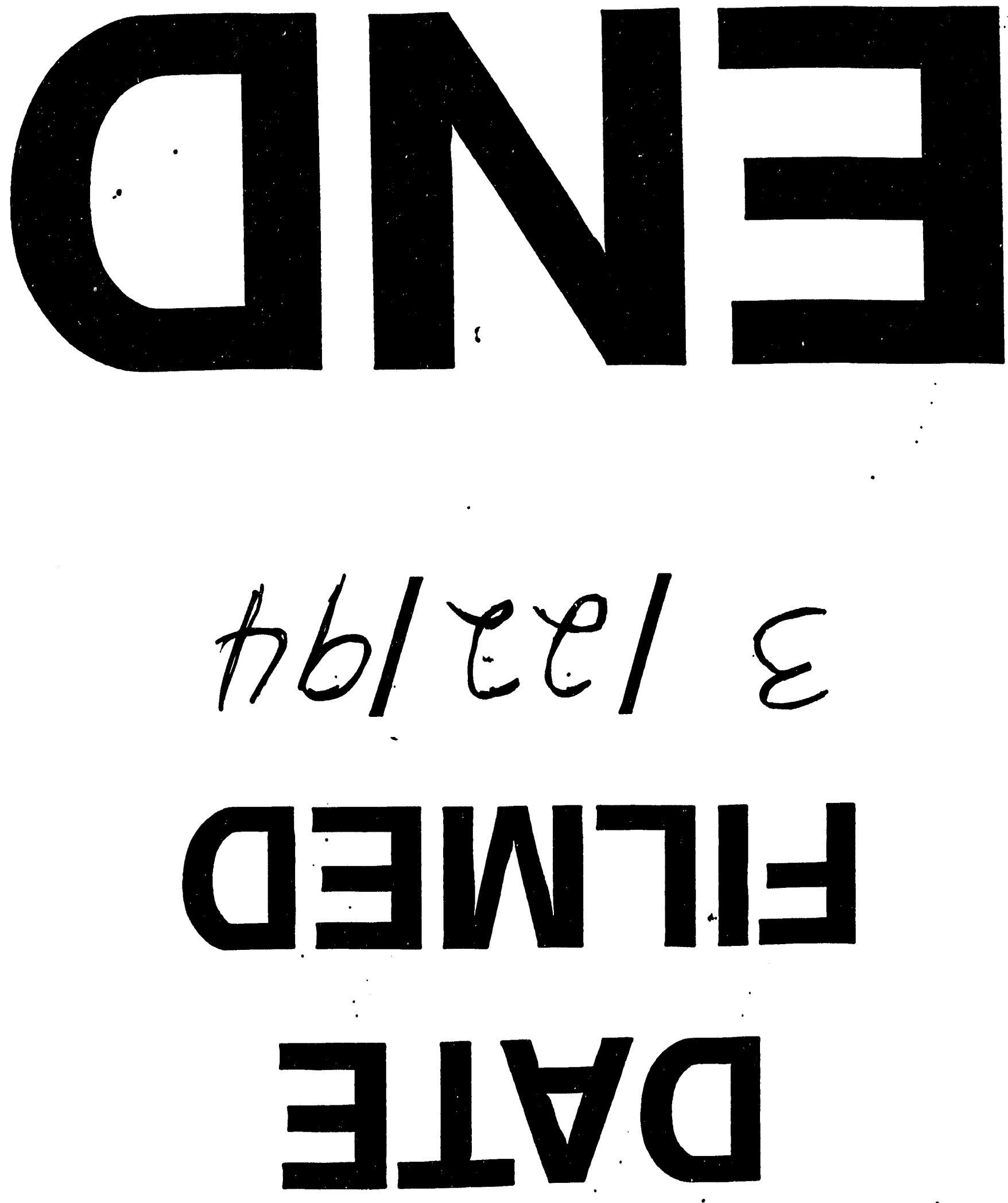


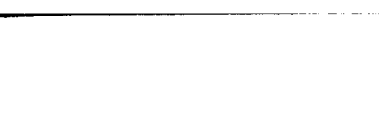

